\title{
Unordon
}

\section{Global environmental footprints}

A guide to estimating, interpreting and using consumption-based accounts

of resource use and environmental impacts

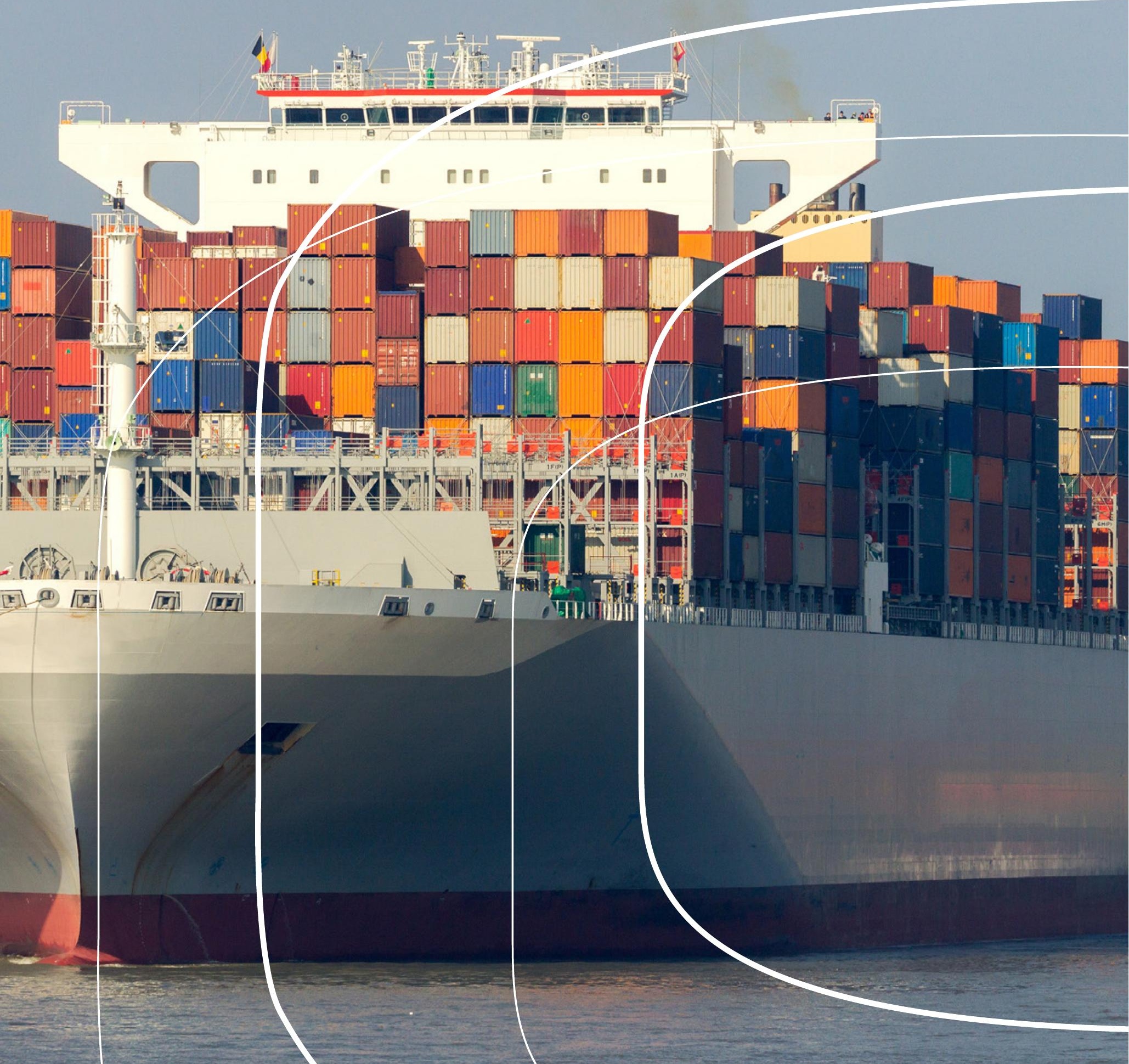







\section{Global environmental footprints}

A guide to estimating, interpreting and using consumption-based accounts of resource use and environmental impacts

Glen P. Peters, Robbie M. Andrew and Jonas Karstensen

TemaNord 2016:532 


\section{Global environmental footprints}

A guide to estimating, interpreting and using consumption-based accounts of resource use and environmental impacts

Glen P. Peters, Robbie M. Andrew and Jonas Karstensen

ISBN 978-92-893-4629-0 (PRINT)

ISBN 978-92-893-4630-6 (PDF)

ISBN 978-92-893-4631-3 (EPUB)

http://dx.doi.org/10.6027/TN2016-532

TemaNord 2016:532

ISSN 0908-6692

(C) Nordic Council of Ministers 2016

Layout: Hanne Lebech

Cover photo: Scanpix

Print: Rosendahls-Schultz Grafisk

Printed in Denmark

This publication has been published with financial support by the Nordic Council of Ministers. However, the contents of this publication do not necessarily reflect the views, policies or recommendations of the Nordic Council of Ministers.

www.norden.org/nordpub

Nordic co-operation

Nordic co-operation is one of the world's most extensive forms of regional collaboration, involving Denmark, Finland, Iceland, Norway, Sweden, and the Faroe Islands, Greenland, and Åland.

Nordic co-operation has firm traditions in politics, the economy, and culture. It plays an important role in European and international collaboration, and aims at creating a strong Nordic community in a strong Europe.

Nordic co-operation seeks to safeguard Nordic and regional interests and principles in the global community. Common Nordic values help the region solidify its position as one of the world's most innovative and competitive.

Nordic Council of Ministers

Ved Stranden 18

DK-1061 Copenhagen K

Phone (+45) 33960200

\section{www.norden.org}




\section{Contents}

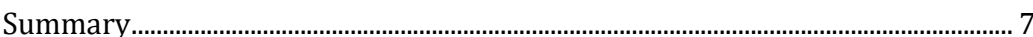

Summary of the key messages....................................................................................... 8

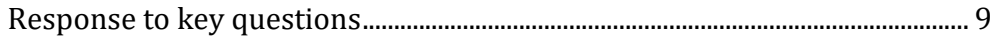

Preface ......................................................................................................................................15

1. Introduction ........................................................................................................

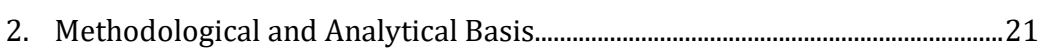

2.1 Environmental Footprints ......................................................................21

2.2 Estimating national-level environmental footprints ............................26

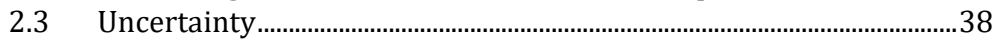

3. The policy relevance and application of environmental footprints..............45

3.1 Carbon and greenhouse gas footprints.........................................................

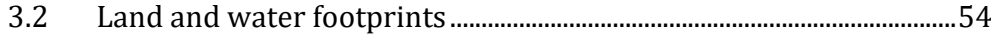

3.3 Material footprints.......................................................................................61

4. Using environmental footprints in policy.......................................................6

4.1 Uncertainty and reliability...........................................................................68

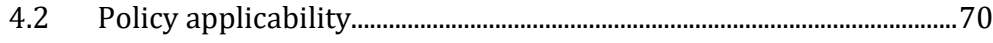

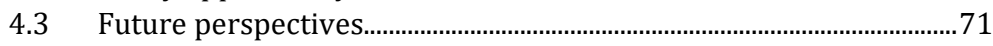

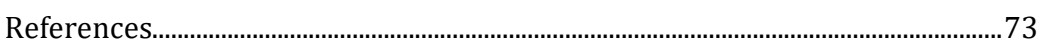

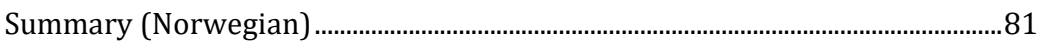




\section{Summary}

"Environmental flows" (emissions and resource use) are typically allocated to national territories since that is where national governments have jurisdiction both to monitor and to apply policies. This allocation typically leads to "production-based policies", as environmental flows generally - but not always - occur at the location where goods and services are produced.

However, in an increasingly globalised world there has been an increased interest in allocating environmental flows to final consumption instead, leading to an "environmental footprint". An environmental footprint can be conceptualised as the national territorial flows, plus flows occurring in other countries related to the production of imports, minus domestic flows related to the production of exports.

For most environmental flows, developed countries have larger environmental footprints than their national territorial flows, making developed countries "net importers" of environmental flows. This "net import" has tended to increase ever since estimation of environmental footprints started two decades ago. An exception to this general rule are developed countries which are net exporters of raw materials (e.g., Australia, Canada and Norway) and many least developing countries (LDCs).

The "net import" is a result of developed countries increasing their consumption while other countries increase their production and emissions. It has been suggested that this reduces the effectiveness of environmental policies, and that policies therefore should address the environmental footprint rather than just domestic flows.

While there is a significant research on methodologies to estimate environmental footprints and decompose the resulting estimates, there is very little research on policy applications. Most policy research has been on greenhouse gas emissions and using trade measures (e.g., border carbon adjustments) to shift climate policy to a footprint perspective.

Environmental footprints improve our understanding of the role of consumption and international trade on environmental problems. This gives greater understanding to consumers and policy makers, and disaggregated time series of environmental footprints provide an important baseline for potential future policy applications. However, policy applications of environmental footprints are limited by estimation 
and interpretation uncertainty, and the lack of a clear motivation for policy makers to pursue policies based on environment footprints.

\section{Summary of the key messages}

- The definitions of different "environmental footprints" vary, and the definitions are not necessarily tailored for policy relevance.

- There are many different methods to estimate environmental footprints, but we recommend "multi-regional input-output analysis" for national environmental footprints, as it is comprehensive, consistent with the "System of National Accounts", and links to the final consumption of goods and services.

- The data requirements are immense and complex, but several groups have constructed global datasets independently, and often these datasets are available publicly.

- Reliability and uncertainty remain persistent issues, despite greater understanding in recent years, and this limits policy applications.

- Environmental footprints have been primarily driven by research interests, and a focus on policy implementation may require different levels of aggregation and analytical focus.

- It is important to monitor, report, and verify key environmental footprints to understand the role of consumption in driving environmental problems, tracking progress, informing policy, and developing baselines and expertise for potential policy implementation.

- For policy applications of national environmental footprints, it is important to delineate what policies may be additional compared to a conventional territorial or production approach.

- Carbon footprints have the most obvious policy applicability compared to other footprints, but it is unclear whether the potential gains offset the potentially large "transaction costs".

- Many environmental footprints pertain to environmental problems that are best dealt with locally (land and water use) and, apart from providing additional understanding, the policy utility of the corresponding environmental footprints may be limited relative to the standard territorial approach. 


\section{Response to key questions}

The project objective was to compile a report on the methodological and analytical basis of environmental footprints, as well as challenges and limitations in the use of such estimates for policy. The content of this report responds to specific questions resulting from this objective, and here we give summarised answers to these questions.

\section{What are the data requirements and possibilities?}

To estimate environmental footprints at the country level, a model of global supply chains is required. Most analysts use an economic technique called "Environmentally-extended Multi-Regional Input-Output Analysis". These models essentially combine economic data from individual countries and bilateral trade flows to build a representation of global supply chains in a given year. Despite the necessity to balance large amounts of often conflicting data, several groups now independently construct these datasets. Once this data is in place, it is technically possible to estimate a variety of different environmental footprints.

Some environmental footprints, particularly for material, land, and water use, are estimated using direct trade flows often known as "apparent consumption" or "domestic material consumption". These methods use a truncated version of global supply chains, but can have more detail at the product level. There can be significant differences between environmental footprint estimates using full supply chains and direct trade flows.

\section{How to use and interpret such estimates and calculations?}

Environmental footprints give an estimate of the total environmental flows allocated to consumption. Often, the motivation is to compare the environmental footprint with the territorial flows, and deduce whether a country is a net importer (footprint higher than territorial flows) or exporter (footprint lower than territorial flows). Further, it is of interest if the net import/export is increasing or decreasing over time.

Since countries participate in international trade and specialise in some forms of production given their geographic and historical context, a country may naturally be a net exporter or importer. Small countries, lacking native resources, tend to be net importers of most environmental flows, and this is true for both rich and poor countries. Thus, one should not generalise that it is necessarily negative if a country is a net importer of an environmental flow. 
The net export or import may be interpreted differently for different environmental footprints. An increasing net import of greenhouse gas emissions may represent inefficiencies of global climate policy ("carbon leakage"), while an increasing net import of materials may represent decreasing resource efficiency.

Environmental footprints often provide considerably more information than standard environmental accounts, and have broader applications than just comparing environmental footprints with territorial accounts. Understanding the different sectoral distribution of the environmental footprints (e.g., services and light manufacturing) compared to territorial sectoral distribution (e.g., electricity and heavy industry) may give new understanding of production and consumption systems and provide insight into alternative policy instruments that address consumption.

\section{With what degree of certainty and reliability?}

There have been several studies that have addressed certainty and reliability, and they often conclude that environmental footprints are more certain and reliable than generally assumed. The uncertainty in an environmental footprint can be of a similar magnitude to the uncertainty in national territorial flows. Studies tend to agree on whether a country is a net importer or exporter, and broadly have similar trends over time, but the absolute magnitude of the environmental footprint may vary by study. At the more detailed level (e.g., sectors), there can be large difference between independent estimates and uncertainties can be larger. Given the uncertainties at the detailed level, the policy applications available for different environmental footprints may be limited.

Despite these broad positive conclusions, existing analyses of certainty and reliability of environmental footprints have probably been over-simplified and have not adequately considered the differences between independently constructed datasets and the potential for larger uncertainties than currently assumed. Indeed, uncertainty analysis has often focused on large countries where uncertainties are smaller or used aggregated measures of uncertainty. Uncertainties may be more significant for small or developing countries, or countries with unique economic structures. Correlations are rarely included in uncertainty analyses, and this may lead to underestimates of uncertainties. There are also significant issues with system boundaries, particularly in how international transportation is included in different datasets or variations 
in definitions of the environmental accounts. Thus, we recommend a cautious approach to environmental footprint uncertainty.

\section{With what validity for illuminating critical environmental goals, targets and boundaries?}

Environmental goals, targets and boundaries can already be illuminated using estimates of territorial environmental flows. A shift to an environmental footprint will increase the flows for some countries, but decrease the flows for other countries, but with the same global total regardless of the form of allocation. Environmental goals, targets and boundaries are dependent on scale and the policy context.

For a global environmental issue, like climate change, environmental footprints could be used for goals, targets, and boundaries, but where the basis of those goals is shifted from a territorial perspective to a consumption perspective. For local environmental issues, like local water pollution, the environmental footprint of one country includes local environmental issues in another country. Since the environmental issue is local, the spatial disconnect between the two countries may limit the policy relevance of a global environmental footprint.

In comparison to existing territorial flows, the application of environmental footprints to goals, targets, and boundaries may be limited depending on the particular environmental flow. Careful specification of the goal, targets, and boundaries is required to delineate whether the standard national territorial flows or environmental footprints are most relevant.

\section{What are the differences between environmental footprint for carbon dioxide emissions and land, water, energy and material use?}

The different environmental footprints broadly serve different environmental and other policy objectives.

Greenhouse gases are global pollutants; their climate impacts are essentially independent of the location of the emission source. Due to the fragmented implementation of climate policy, international trade flows can change (c.f., "carbon leakage") and consumption-based policies may help improve the environmental effectiveness and economic efficiency of unilateral climate policies.

Land and water footprints may address both resource use and some types of (local) pollution. Due to different climatic ranges, it is expected 
that most countries will have an imbalance (net export or import) of land and water use. Globally, the land and water use is larger if countries do not trade in agricultural products, and thus there are potentially large savings in land and water use from appropriate international trade. Land and water footprints can nevertheless be an important tool to address issues of food and fuel security (e.g., climatic impacts on key agricultural regions) or the benefits of shifting consumption patterns (e.g. lower meat consumption).

Material and energy footprints may address both resource use and some types of (local and global) pollution. For resources, poor material and energy efficiency may indicate potential savings that can be captured through productivity improvements, and may highlight security of supply issues. For energy, it is arguably more appropriate to focus on dedicated footprints on, e.g., greenhouse gas emissions or local pollutants.

\section{What is the significance for policy of differences between renewable and non-renewable resources, and between local resources and issues (e.g., water) and global (e.g., carbon)?}

Renewable resources (e.g., water) may not have hard limits, while nonrenewable resources may (e.g., fossil fuels). However, renewable resources can also be degraded (polluted), have flow limits (e.g., restricted daily usage), and be used more efficiently (e.g., improved productivity). There is utility in tracking environmental footprints for both renewable and non-renewable resources, but the corresponding policy relevance may be quite different.

Likewise, environmental footprints of local and global environmental issues have different policy applications. There is clearer policy relevance to environmental footprints for global environmental problems, such as, greenhouse gas emissions. For local environmental problems, the importing country may have limited policy incentive to regulate another countries local environmental problems other than for ethical and moral reasons (e.g., consumption causing air pollution in a developing country), policy coherence (e.g., desire to ensure that local policy on air pollution is not shifted to another region), and efficiency (e.g., reduced consumption may have local economic benefits). Since policies on environmental footprints inevitably may influence trade flows, the economic benefits of trade have to be balanced with the environmental and social consequences, particularly for developing countries.

Some environmental problems have quite different temporal profiles. Greenhouse gas emissions are growing rapidly, and thus there is a greater 
propensity for issues such as "carbon leakage". Global land and water use, on the other hand, have remained relatively constant over time (and have biophysical limits), and the propensity for burden shifting is lower. Further, land use, water use and some greenhouse gas emissions are driven by food consumption, which stabilises at certain income levels (Engel's law), while most greenhouse gas emissions and material consumption are driven by increased consumption of material goods and services which increases with income.

\section{The need for advice and recommendations on how and where to differentiate between different fractions and subcategories of environmental footprints, particularly of materials (fossil fuels, biomass, aggregates, and minerals) and water (green, blue, and grey)}

In general, aggregation of different fractions or subcategories may make the policy discussion simpler and easier to communicate, but it also hides potentially useful or necessary information. For example, an increasing material footprint may only apply to a subcategory (e.g. natural gas) and policies could be misdirected if it is assumed the subcategory generalised to the aggregate. Further, some categories may be more useful for some environmental issues and some policy questions (e.g., green vs blue water). As a general principle, fractions and subcategories should be shown, especially if one fraction or subcategory has a different trend to others.

\section{To what extent, and for which purposes, can footprint methodology be used in policy formulation, and what are the main limitations and barriers for such use?}

The usefulness for policy will vary with the type of environmental footprint. As a minimum, there is great value in tracking environmental footprints over time. Environmental footprints act as a useful baseline, and may indicate areas of concern or where policies are needed in the future. Indeed, policies and policy content can change over time and the need for environmental footprints could come and go, leading to the need for long-term monitoring, reporting, and verification.

For example, the recent Paris Agreement (climate policy) requires all countries to contribute to mitigation, so many concerns of unilateral climate policy (carbon leakage) may no longer be as pressing. However, in several years, some countries may withdraw from the Paris Agreement or show limited progress, motivating alternative policy approaches. 
Having a long baseline and updated datasets may allow for a quicker policy response.

Further, environmental footprints emphasise different sectors and products leading to environmental flows, and long baselines can be used to track changes over time. A large net import of water may come as a surprise, but it may also represent a long term, and even decreasing, trend. A large land footprint may indicate large pasture rangelands in the supply chain, something that may have low environmental impact or could change rapidly with policy, increased intensification or changing consumption patterns.

\section{How can footprint indicators best be further developed to improve their level of certainty for these purposes?}

Environmental footprints have many advantages that may not be obvious at first. The construction of datasets to estimate environmental footprints (multi-regional input-output tables) is an exercise in managing conflicting information. Just as input-output tables are used in the system of national accounts in many countries, the construction of multi-regional inputoutput tables can be used to improve international economic statistics. The continued development of global models should be encouraged, but more emphasis should be put on enumerating the uncertainties of the datasets.

A variety of improvements are needed for territorial environmental accounts, as these are one of the biggest sources of differences across independent estimates of environmental footprints. Even in well-studied areas like greenhouse gas emissions, there is high variation between environmental accounts at the territorial level. For the other environmental footprints, data may only exist from one study or from one year, requiring crude estimates to track environmental footprints adequately over time.

There has been much less research on using environmental footprints in policy. Tracking progress is one useful policy application, but there is little research outside of climate policy on how to reduce environmental footprints over time. It is often not clear what the objectives may be for reducing some environmental footprints, as they may just represent different economic structures of different countries in a globalised world. Indeed, international trade may act to reduce the overall environmental footprint (as has been shown for carbon dioxide, and land and water use). 


\section{Preface}

The idea of "footprinting" global environmental impacts has been discussed for some time now. Our working group in 2010 published an earlier report on global carbon footprints. This concept was at the time attracting a considerable amount of attention from the scientific community as well as the general public. The aim of that project was to estimate the consumptionbased carbon footprints generated by the Nordic countries, using, and comparing, alternative methods. One conclusion was the lack of consistency and agreement within the scientific community on definitions and methods - which often caused widely divergent results. The study concluded that footprinting required quite specific and high quality data on both resource inputs and multiregional trade flows, and that a lot of work was still needed in order to make such estimates and calculations consistent and - perhaps most importantly - policy relevant.

Now, six years later on, the Working Group on Environment and Economy revisits the concept of environmental footprints, for both carbon and a wider range of other environmental and resource issues, to see how definitions, methods and data requirement issues have developed. Public interest in this type of measurements has continued to increase, and demand- or consumption-based indicators or footprints are central both to the OECD's work with indicators for Green Growth and the European Union's work with indicators for resource productivity and the circular economy. Hence, we argue that it is important to understand what these estimates can tell us, how they can be produced and in what ways they might be used to inform policy development.

The report has been written by researchers at the Center for International Climate and Environmental Research - Oslo (CICERO). All results and conclusions are those of the authors.

June 2016

Fredrik Granath

Chairman of the Working Group

on Environment and Economy

under the Nordic Council of Ministers 


\section{Introduction}

Environmental policy has traditionally been implemented from a territorial perspective, addressing environmental flows at the source (e.g., emissions from a tailpipe). ${ }^{1}$ This is intuitively appealing for two related reasons. First, to analyse environmental flows the source of the environmental flows needs to be known (e.g. for atmospheric transport modelling), leading to good datasets on sources. Second, policy makers have jurisdiction over environmental flows originating in their own borders and can therefore implement policies. Since the source of environmental flows is often at the point of production (e.g., factory) a territorial perspective generally leads to a focus on producers, consequently a "territorial" and "production" perspective are often synonyms.

In recent years, there has been growing interest in analysing environmental policy from a consumption perspective. In the 1960's, Georg Borgström studied the land requirements for food production and used the term "ghost acreage" (Borgström, 1965). Around 1970, Ayres and Kneese (1969) and Leontief (1970) analysed how environmental flows can be "transferred" along supply chains from the producer to consumer. Since the mid-1970's, economists have been analysing unilateral environmental policies and developed associated policy instruments (Markusen, 1975), most generally applied to "carbon leakage" in a climate policy setting (Felder and Rutherford, 1993, Wyckoff and Roop, 1994). In the 1990's, Wackernagel and Rees (1996) developed the concept of an ecological footprint to measure society's impact on the planetary system. These, and possibly other, largely independent strands of literature culminated in what is now known as "consumption-based accounting", "consumer perspective", "consumer responsibility", "embodied/embedded flows", and "environmental footprints". ${ }^{2}$ Today, there exists footprints for numerous environmental flows, but particularly greenhouse gas emissions and water, land, and material use. In addition, footprints span different spatial scales (Peters, 2010a), from

\footnotetext{
${ }^{1}$ We refer to "environmental flows" to collectively mean emissions, water use, land use, material use, etc. 2 The term "footprint" is regularly misused to represent any environmental flow whether based on production or consumption.
} 
life cycle assessment of individual items (e.g., diapers) to consumptionbased accounts of countries.

The footprint literature has been largely empirical, with relatively little attention paid to practical applications in policy. Most policy interest has been at the national level, where footprints can be seen as tradeadjusted (imports minus exports) national flows. Territorial flows may be misleading indicators of environmental flows, as in a globalised world, a large share of an environmental footprint may originate in direct or indirect trade partners. Studies show that for many environmental flows, developed counties are net importers of environmental flows and the size of the net footprint is increasing over time. This indicates that environmental improvements in developed countries come at the expense of environmental harm in developing countries (Kanemoto et al., 2014). In response to this, there have been suggestions for the greater use of environmental footprints in policy.

Despite the growing interest in environmental footprints in the research community, there has been relatively little uptake in the policy community. Most policy interest has been in using environmental footprints as an indicator of progress, particularly in the context of green growth and efficiency or productivity improvements (OECD, 2011). The terminology of "sustainable production and consumption" has increasingly appeared in EU documents (European Commission, 2011). However, this has rarely led to concrete policies, particularly policies that are over and above what might be implemented from a production perspective.

Existing studies show that environmental footprints are useful as a supplement to production-based indicators and make a clear case for communicating results of environmental footprint studies and for raising awareness of the impacts of consumption. However, the use of environmental footprints as "official" indicators requires sufficient accuracy, replicability, and timeliness. Despite the proliferation of databases relevant for environmental footprints, one can still debate how suitable existing databases are for these purposes. It is less clear how environmental footprints may have applications that extend beyond monitoring. Framing policies around environmental footprints requires a clear motivation and objective, and that is still lacking in many cases, with the exception of climate policy.

This report focuses on environmental footprints at the national level. Since the primary motivation of national-level environmental footprints is the export/import adjustment, we focus on the opportunities and challenges that these adjustments may bring to the policy maker. We do 
not discuss policies on consumption that are unlikely to directly modify the import component of an environmental footprint.

The report is split into two core chapters: Chapter 2 focusses on methodological aspects, leading to discussions about uncertainty and reliability. Chapter 3 focuses on the policy motivation and options, covering primarily climate (greenhouse gases) and materials, land, and water use. A final chapter makes some more direct recommendations and highlights key knowledge gaps. 


\section{Methodological and Analytical Basis}

Before policies can be implemented, it is beneficial to have a system of Monitoring, Reporting, and Verification (MRV) so that progress can be tracked. Since the estimation of environmental footprints requires combining different data sets, some of which are conflicting, the resulting footprints will be uncertain. Further issues arise in terms of the timeliness of estimates and whether the level of disaggregation is adequate for policy needs. In this chapter, we first give a brief background of "environmental footprints", before discussing the key methods and necessary data to estimate environmental footprints. Finally, we discuss several aspects of uncertainty, and what that may mean for the reliability of estimates used in policy.

\subsection{Environmental Footprints}

Environmental footprints have been the topic of numerous studies in the last decade. The concept of an environmental "footprint" was first developed for land use under the term "ghost acreage" (Borgström, 1965), but not long after a generalised framework for all environmental flows was developed independently by Ayres and Kneese (1969) and, recipient of the Nobel Memorial Prize in Economic Sciences, Leontief (1970). The term "footprint" was coined and popularized in the 1990s after the development of the "ecological footprint" (Wackernagel and Rees, 1996, Rees, 1992). Today, the term "footprint" is used for many different environmental flows (Hoekstra and Wiedmann, 2014), but there remains no single, accepted definition of an "environmental footprint" and definitions often vary with method and scale (Peters, 2010a). The term "footprint" is also often erroneously used to refer to any environmental flow, whether based on production or consumption. 


\subsubsection{Definitions}

For the purpose of this report, we define an "environmental footprint" conceptually as the (global) environmental flow caused by economic consumption activities at the national level, including the flows in all direct and indirect production processes. We use a conceptual definition, as there are often variations in the definition depending on the environmental flow and methodology. Broadly speaking, a footprint can be estimated for any environmental flow, but we focus on carbon dioxide and land, water, and material use.

The environmental footprint relates to the consumption of goods and services (products), and when aggregated to the national level, an environmental footprint is conceptually the "territorial" flow (often called "production"), minus the environmental flow from the production of exported products, plus the environmental flow from production in other countries (imports) (Figure 1). Many different names are used for a footprint, including "consumption-based accounting", "consumer perspective", "consumer responsibility", "embodied/embedded flows", and "environmental footprints".

Figure 1: National emissions accounting: production (territorial) flows include emissions generated in the production of exports, while consumption accounts exclude exports but include imports. "Domestic" refers to domestic production for domestic consumption (excluding production for exports)

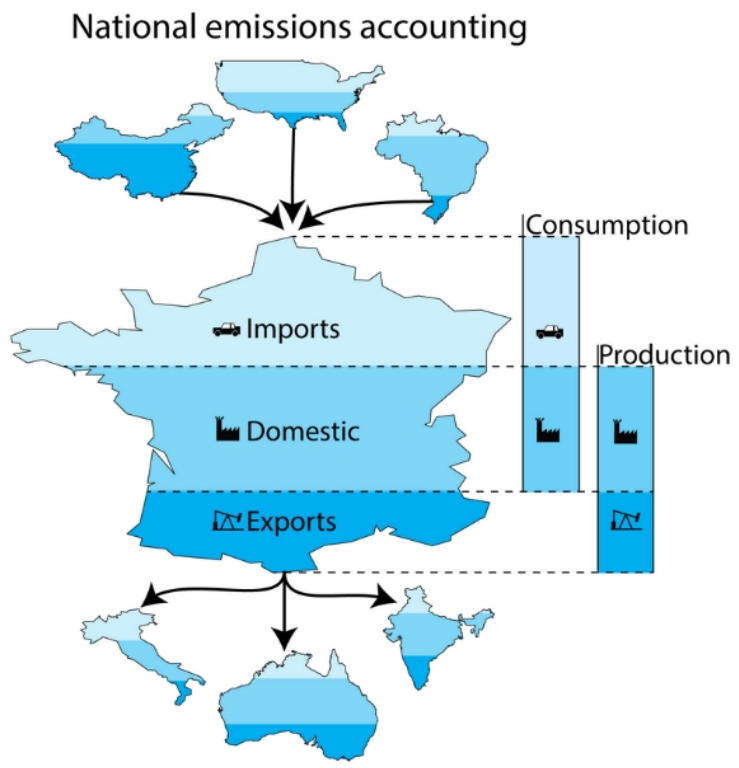

Source: Cuypers et al. (2013). 
One reason that we only give a broad conceptual definition of an environmental footprint is that the definition can subtly change between alternative footprints, even with the same method. First, the environmental account can contain different "flows":

- Physical (embedded): A material physically moves from production to consumption along the supply chain. Examples include water physically in melons or the carbon in coal.

- Virtual (not embedded): A material may be "extracted" or "used", but not flow with the product. Examples include emissions to air, land use, and most types of water use.

The use of the two terms "embodied" and "embedded" has perhaps led to some confusion (Smil, 2008). We use "embedded" for the physical content of a product, while "embodied" for the "virtual" (non-embedded) content.

Different methods can include all of the supply chain or direct trade flows, leading to different definitions of consumption:

- Apparent consumption: The flow at the national level is adjusted for direct international trade flows only (minus exports plus imports).

- Final consumption: The flow at the national level is allocated to final consumption including the full supply chain starting at production and ending at final consumption. "Final consumption" is defined in the system national accounts as "goods and services used up by individual households or the community to satisfy their individual or collective needs or wants".

The term "environmental footprint" can be based on all combinations of the above, and it can be often unclear what is included in any given footprint and what the policy relevance of different definitions are.

\subsubsection{Key environmental footprints}

Environmental footprints have been estimated for many environmental (and economic) flows, and here we briefly discuss some of the most common together with some of their key characteristics.

Carbon and greenhouse gas footprints: Carbon or greenhouse gas footprints are the most common footprints appearing in the literature, and have been applied at multiple scales (Peters, 2010a). Carbon footprints are the most common probably because of their policy salience as a global environmental problem. Particular attention has been given to 
consumption patterns (Hertwich and Peters, 2009), trade flows (Davis and Caldeira, 2010), and how the trade flows change over time (Peters et al., 2011b). Extensions have been made to cover all air pollutants (Kanemoto et al., 2014) and even temperature change (Karstensen et al., 2015a). Carbon footprints are almost always based on "embodied flows" and "final consumption".

Material Footprints: Material footprints are generally estimated using one of two distinct methods (Wiedmann et al., 2015). The first method follows "physical flows" using "apparent consumption", and is often termed Domestic Material Consumption (DMC). This method starts with the extraction of materials, and then subtracts the physical flows of materials exported and adds the physical flow of materials imported. Using this method, the material is physically transported from extractor to consumer, but only along direct trade flows. A second method, as used for carbon footprints, is to estimate the "physical and embodied flows" using "final consumption" (Wiedmann et al., 2015). This method allocates materials along the supply chain, and thus some material may be physically transported (e.g., biomass in a chair) and some may be virtually transported (e.g., waste in the production of a chair). The differences between the two methods, apparent consumption versus final consumption, is due to both the more complex supply chains in final consumption studies (Peters et al., 2012) and the inclusion of embodied flows (Wiedmann et al., 2015) like mine tailings. Material footprints may include metal ores, fossil fuels, construction minerals and biomass, either aggregated or separated (Wiedmann et al., 2015).

Water Footprint: The water footprint of national production is defined as the total freshwater volume consumed or polluted within the territory of the nation as a result of activities within the different sectors of the economy (Hoekstra and Mekonnen, 2012). The water footprint distinguishes between consumptive use of rainwater (green, used directly from the soil by plants), ground and surface water (blue, transported by irrigation or used in industry) and volumes of water polluted (grey, estimated as the amount of water required to sufficiently dilute pollution). Different methods are used to estimate water footprints. First, "physical and embodied flows" of individual products are transferred with the "apparent consumption" (Hoekstra et al., 2011). A second approach is to estimate water use by sector and then allocate "physical and embodied flows" to final consumption (Lenzen et al., 2013). In both cases, water scarcity can be introduced into the concept (Lenzen et al., 2013). These two methods are analogous to the two methods described in material footprints. 
Land Footprint: The land footprint assesses the domestic and foreign land areas that are directly and indirectly required to satisfy national final consumption (Giljum et al., 2013). The land footprint can be based on actual "physical" areas of land (Cuypers et al., 2013), in contrast to the Ecological Footprint approach that weights land according to its bioproductivity (Weinzettel et al., 2013). Land is often separated into cropland, pastureland, and forestland. As for water and material footprints, the "physical" land (or modified version in the Ecological Footprint) can be based on "apparent consumption" or "final consumption" (Cuypers et al., 2013).

Ecological Footprint: The Ecological Footprint is an aggregated measure of humanity"s appropriation of total available "carrying capacity" (Rees, 1992, Wackernagel, 1994). The ecological footprint includes land areas used by humans to produce food and fibre, urban areas, an equivalent area representing the marine fish harvest, and the area that would be required if all $\mathrm{CO}_{2}$ emissions were to be absorbed by additional forests. All indicators are converted to an areal unit, the "global hectare," and then summed and compared to the Earth's biocapacity, defined as the area actually available to produce renewable resources and absorb $\mathrm{CO}_{2}$. This makes the ecological footprint an indicator of sustainability. According to the most recent global estimate, in 2010 the Footprint exceeded the Earth's biocapacity by about 50\% (WWF, 2014). The ecological footprint has received significant criticism (van den Bergh and Grazi, 2014). The method has been based on "apparent consumption" (most common) and "final consumption" (Wiedmann and Lenzen, 2007).

Human appropriation of net primary production (HANPP): This is a composite indicator that attempts to measure "the "scale" of human activities compared to natural processes" (Haberl et al., 2010). Net Primary Productivity (NPP) is the "net amount of biomass produced each year by plants" (Haberl et al., 2010), and the "human appropriation" of NPP reflects both the amount of area used by humans and the intensity of land use. Global HANPP for the year 2000 was estimated to be $24 \%$ of potential net primary productivity (Haberl et al., 2007). Like the Ecological Footprint, HANPP has attempts to use a single indicator to measure the proximity of human society's size to some limit. As with the ecological footprint, HANPP has been criticised (Smil, 2013). The method is usually based on "apparent consumption", though "final consumption" can be used leading to significant differences (Peters et al., 2012).

Economic footprints: Recently, there has been interest in tracing trade in value added (TiVA). Although not initially recognised (Koopman et al., 2014), the methods are the same as used in environmental footprints (Peters, 2008). This leads to a range of new footprints for value added and 
the components of value added (e.g., labour footprint). These "footprints" have been of interest to the OECD and the World Trade Organisation as alternative measures of trade relationships to the standard bilateral trade balances (OECD, 2015). Economic footprints are based on "final consumption".

Various other footprints have been elaborated in the literature using similar methods, for example, air emissions (Kanemoto et al., 2014), biodiversity (Lenzen et al., 2012b), global temperature change (Karstensen et al., 2015a), and many others. We do not go into these in detail in this report, although, they are no less important than the footprints discussed above for each specific environmental issue.

\subsection{Estimating national-level environmental footprints}

There are many methods that can be used to estimate complete or partial environmental footprints. The various methods differ along several dimensions: footprint definition, the level of detail (aggregation), system boundaries, spatial and temporal resolution, data availability, and computational time. The methods span from product-specific Life Cycle Assessments (LCA) to global multi-regional input-output (MRIO) models. In an earlier report (Peters and Solli, 2010), multi-regional input-output analysis was recommended for estimating environmental footprints at the national level due to completeness and consistency. We refer the reader to that report for a more detailed discussion of the reasons behind that choice.

An Input-Output Table (IOT) is a component of the national economic accounting system that summarises all bilateral transactions between sectors in an economy (United Nations et al., 1993). As such, Input-Output Analysis (IOA) is a powerful method to assess the relationship between different parts of the economy and for understanding the consequences of an impact on the economy (e.g., a flood or a drop in oil price), sometimes in combination with other modelling tools. The idea of using IOA for environmental calculations was first developed in 1970s (Leontief, 1970, Ayres and Kneese, 1969). By linking an IOT to environmental accounts, it is straightforward to estimate the induced economic activity and environmental impacts for different activities, leading to an estimate of the environmental footprint for that activity. The top-down nature of the method ensures completeness (covers the entire economy and supply chain), but the activity detail is limited by the detail 
of the IOT (usually 50-100 sectors in Europe). The method is well suited to estimating national environmental footprints. The main constraints are data availability and harmonisation.

To use environmental footprints in policy requires an understanding of the reliability of environmental footprint estimates. The most important factor influencing the reliability is data, and a short description of the data constraints is necessary to frame later discussions about reliability. In this section, we discuss the core components needed to estimate environmental footprints using Multi-Region Input-Output (MRIO) analysis (Figure 2). The first step is to obtain environmental accounts for each country and sector, (section 4.2.1). The second step is to compile economic accounts, here taken as an MRIO table, to link global production and consumption (section 4.2.2). A final step is to potentially aggregate to the environmental footprint (section 4.2.3). We draw on the language and definitions used by Eurostat in their National Accounting Matrix with Environmental Accounts (European Commission, 2001).

While this report is largely based on the use of economic data to estimate environmental footprints, it is worth explaining another relevant method applicable at the national level. Environmental footprints for materials, water, and land use are often estimated using "apparent consumption", also termed Domestic Material Consumption (DMC). Apparent consumption starts with the estimated material, water, or land use at the point of extraction (materials) or production (land and water). From the point of extraction or production, direct trade flows are used to adjust to consumption, where consumption is estimated as extraction or production minus the flows in exports plus the flows in imports. 
Figure 2: Schematic flow diagram showing how "environmental footprints" are estimated and the data required. Note that the vertical arrows do not represent causation, but represent the general order that calculations are performed

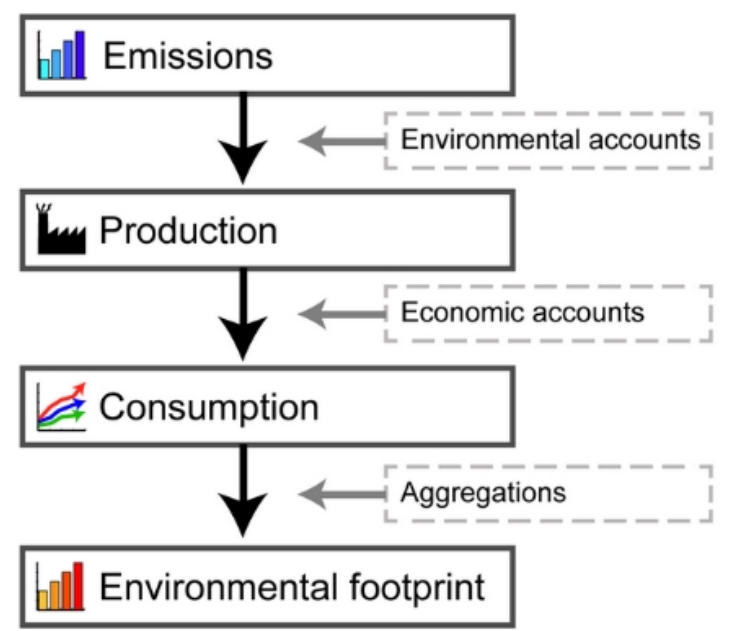

Source: Karstensen et al. (2015b).

Environmental footprints based on MRIO use "actual consumption" defined in the economic sense, that is, the consumption of goods and services. In this method, material, water, and land use is allocated to economic sectors (often the aggregation of individual products) and then transferred along the global supply chain to the consumer. This methodology includes a much more expansive view of the supply chain, including multiple (infinite) layers in the supply chain. Consequently, MRIO allocates much more of the environmental flow to trade flows, often leading to a greater difference between environmental flows allocated to national territory or to consumption (Peters et al., 2012). Because of the more expansive supply chain, services sectors can often be a large share of environmental footprint. Generally speaking, the advantage of the apparent consumption is the possibility to have much more disaggregated and understandable environmental accounts, while the advantages of actual consumption is the complete analysis of the supply chain linking to the "final" consumption initiating the supply chain.

\subsubsection{Environmental accounts}

The starting point of environmental footprints is an estimate of the environmental flows on national territories and offshore areas over which the country has jurisdiction ("territorial accounts"). The existence of these accounts is a result of existing policy goals. In footprint analysis, 
since the territorial accounts are to be linked to input-output tables, they technically need to be adjusted to have the same system boundary as used in the economic data (defined by the System of National Accounts, SNA). Territorial accounts linked to the SNA are often called a National Accounting Matrix including Environmental Accounts (NAMEA) (Pedersen and de Haan, 2006, UN, 2014), or more colloquially, "production accounts". This terminology is most prevalent in Europe, though many (developed) countries estimate NAMEAs.

Territorial and production accounts are often assumed identical, but in practice, there are important differences in their system boundaries. In some countries and for some environmental flows the differences can be quantitatively significant. In the SNA, "[t]he underlying rationale behind the concept of gross domestic product (GDP) for the economy as a whole is that it should measure the total gross values added produced by all institutional units resident in the economy" (United Nations 1993, paragraph 6.233, italics added). The "institutional units" may act outside their country of residence and this is an important issue in the SNA:

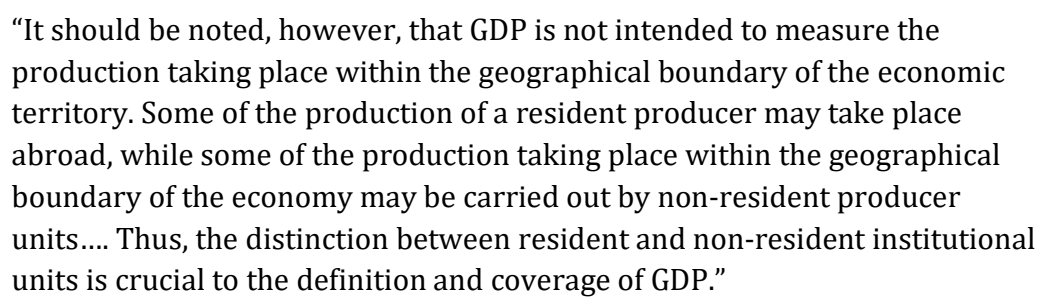
production taking place within the geographical boundary of the economic territory. Some of the production of a resident producer may take place abroad, while some of the production taking place within the geographical boundary of the economy may be carried out by non-resident producer units.... Thus, the distinction between resident and non-resident institutional units is crucial to the definition and coverage of GDP."

(United Nations 1993, paragraph 6.239)

For environmental accounts (NAMEAs), Eurostat publishes a "bridge" table linking the territorial and production accounts, with a Danish example shown in Figure 3. There are two main factors that lead to differences between territorial and production accounts. First, international transport (aviation and shipping) is not formally allocated in a territorial account (as the activity occurs in international territory) but it is allocated in a production account to the resident institution operating the vessel. Particularly for air emissions dependent on fuel consumption, this can lead to substantial quantitative differences. This is a significant issue for the Nordic countries, which often have large shipping industries. Second, resident institutional units often have activities in several countries and these activities should be included in the production accounts (and activities of non-residents excluded). A common example in European countries is the purchase of cheaper transportation fuel in a second country whilst most of driving occurs in 
the country of residence. Due to the difficulty in estimating these accounts, it is often assumed that resident activities cancel the nonresident activities.

\section{Figure 3: The difference between official Danish carbon dioxide emissions reported according to a territorial definition (UNFCCC, dark blue) and an economic definition (NAMEA/NACE, black line). In the case of the Nordic Countries, the "national residents abroad" (light blue) is usually} international shipping and aviation

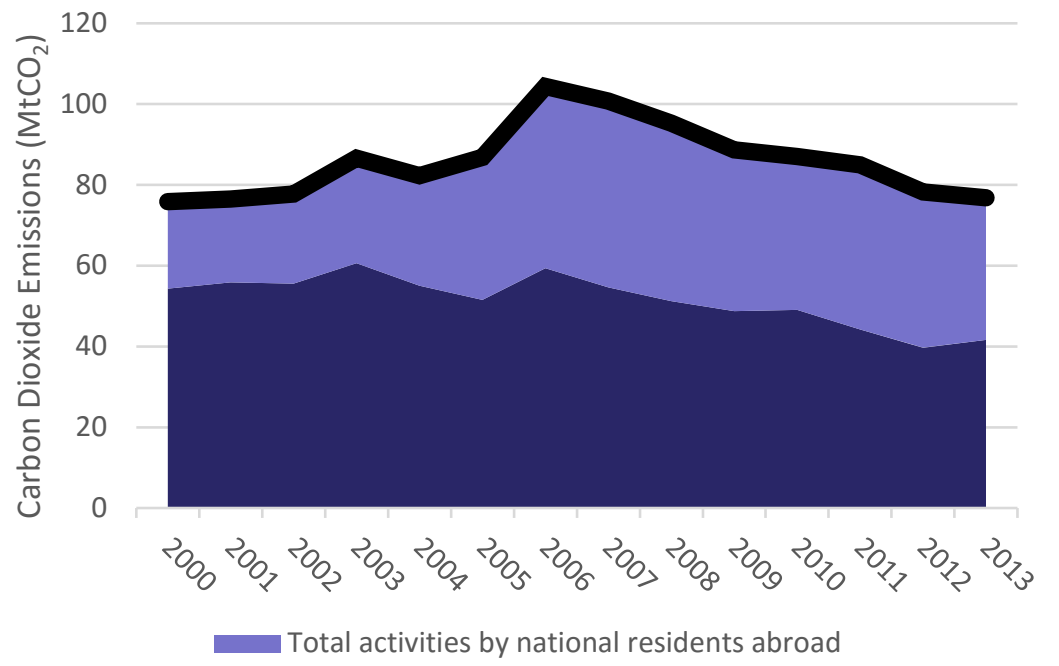

Source: Eurostat.

The effort required to generate environmental accounts can be significant. Some countries only officially report environmental accounts on an irregular basis, if at all, and documentation can be lacking. European countries are an exception, where environmental accounts are reported on an annual basis. Due to the lack of data in some countries, and in order to obtain consistency across countries, analysts frequently estimate their own environmental accounts with documentation often lacking. Consequently, understanding the differences between environmental accounts produced by different groups is often particularly difficult.

Generally, environmental accounts are estimated by combining activity data (e.g., consumption of oil) with an emission factor (emissions per unit oil). Activity data can vary due to system boundary issues, but also different definitions and methodologies for estimating activities. Likewise, emission factors can vary, with most independent institutes using global default emission factors, while national statistical offices usually use country- and sector-specific emission factors. Variations in 
the activity data and emission factors from different datasets can lead to important differences.

Figure 4 demonstrates some of the differences between four independently reported sources of greenhouse gas accounts in the four Nordic countries included in the datasets (Denmark, Finland, Norway, and Sweden). The datasets, and a brief description, are as follows:

- The GTAP consortium provides greenhouse gas data allocated to economic sectors used in the GTAP database and is based on a variety of data sources. Adjustments are made to international transport in an attempt to allocate it to economic activity as required in the SNA. The intention behind the GTAP accounts is to be consistent with the SNA.

- The EDGAR data is allocated to IPCC source sectors, but is reallocated to economic sectors by CICERO, and CICERO further makes an adjustment to international transport to bring it closer to the SNA.

- NAMEA is reported by national statistical agencies as a production account consistent with the SNA, and thus includes international activities of resident institutes.

- UNFCCC is reported by national statistical agencies as a territorial account. The UNFCCC reports data in a source sector classification, and we have not re-allocated it to economic sectors (as this would be a NAMEA). International transport (bunkers) are not allocated to countries in UNFCCC reporting, but are reported as a memo based on the bunker fuels sold (not used by resident institutes as in NAMEAs).

The differences between territorial and production accounts, and different production account estimates from different institutes, can be significant (Figure 4). These differences persist despite relatively harmonized methods and data used to estimate greenhouse gas emissions. The differences are expected to be larger for other environmental accounts where multiple datasets exist. Differences are often in the transport sector (international transport) and mining sector (oil and gas). Since environmental footprints are dominated by the production accounts used as input, variation in environmental footprint estimates from independent organisations can be dominated by differences in production accounts (Peters et al., 2012).

Since NAMEAs are not reported officially in most countries, NAMEA estimates will likely be developed by small groups of researchers (compared to well-resourced statistical agencies), leading to persistent 
uncertainties. Analysts using the GTAP database for environmental footprint estimates will naturally use the GTAP estimates by default. The EDGAR data are often used by organisations due to the consistent coverage across time, countries, sectors, and pollutants. Both the GTAP- and EDGARderived results here may differ significantly from the NAMEAs. Analysts may also compare with the UNFCCC accounts, most familiar to policymakers, which adds an additional layer of confusion to comparisons. The NAMEA and UNFCCC estimates are both officially correct, but can show substantial differences as demonstrated in Figure 3.

Figure 4: Territorial greenhouse gas accounts for the Nordic countries from different sources: GTAP, EDGAR-derived, NAMEA, and UNFCCC. Differences arise from different activity data, emission factors, and system boundaries. The UNFCCC data are not allocated to economic sectors, so we do not show sector results
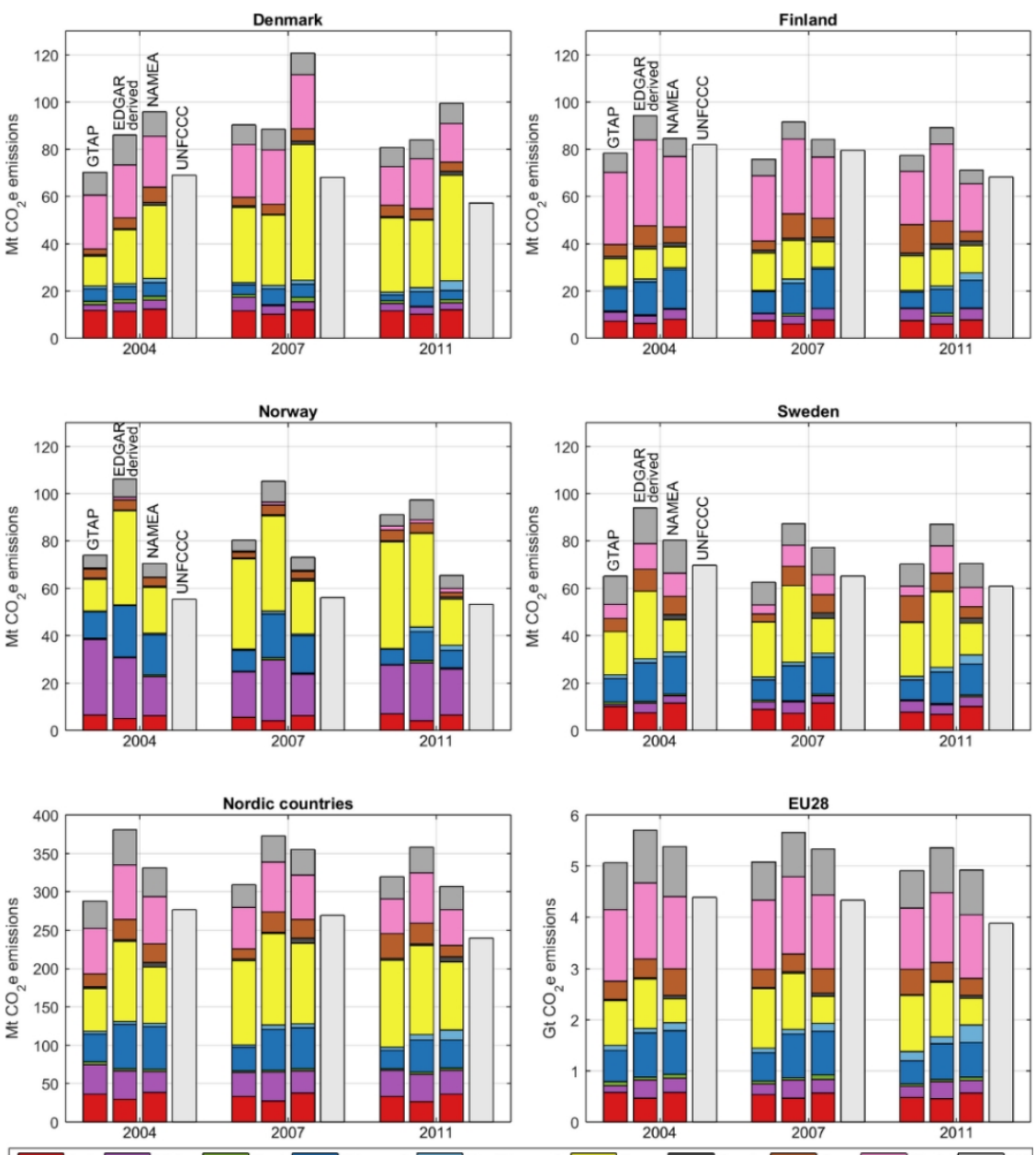

Source: GTAP, EDGAR with own calculations, Eurostat (NAMEA), UNFCCC. 


\subsubsection{Economic accounts}

In the last few years, since the previous Nordic Council report (Peters and Solli, 2010), there has been a significant change in the landscape of MRIO research. Several independent groups have established themselves and produced new global MRIO databases, and some of these are now available for research use without charge, even with pre-calculated footprint results available "off the shelf". There are now five databases in use for environmental footprints (Giljum et al., 2013, Giljum et al., 2015), three of which are freely downloadable, at least for academic use. The scholarly journal Economic Systems Research has devoted a special issue to the construction of MRIOs (Tukker and Dietzenbacher, 2013), and another to a comparison of MRIOs (Inomata and Owen, 2014).

There are several drivers for this surge in activity. First, there was growing recognition of both the feasibility and the utility of such databases. Second, the one global MRIO generally available at the time, GTAP-MRIO, cost a significant amount of money (>1000USD) and moreover required researchers to perform the MRIO construction themselves (Peters and Andrew, 2012), effectively restricting its availability to the broader research community. Third, there was a growing recognition that the input-output tables in the GTAP database were distorted compared with official IOTs, because of the harmonisation process used by GTAP, and this led to growing unease in the research community. And fourth, the development pace and focal points of the GTAP database were not tailored to the demands of the footprint research community.

The construction of MRIO tables is a significant undertaking, requiring the harmonisation of a large amount of data from disparate sources (Tukker and Dietzenbacher, 2013). Specific issues include different pricing systems and margins (basic prices versus retail prices), base years, currency conversion, the use of supply and use tables vs. IOTs, classification schemes and the need for methods to balance conflicting data, estimation of interregional flows, and choices in how to combine disparate data.

\section{Existing MRIO datasets}

In the following we will describe the five MRIO datasets: WIOD, Eora, EXIOBASE, OECD, and GTAP-MRIO. All five databases include Denmark, Finland, and Sweden, as the EU countries are often included in international datasets. Norway is included in Eora, OECD, and GTAP. Iceland is included in Eora and OECD. Greenland is included in Eora only.

World Input-Output Database (WIOD): WIOD was completed in 2012 with funding from the European Union and comprises annual time- 
series of MRIO tables for 40 countries each with 35 sectors from 19952011 (Timmer et al., 2015). Construction prioritised official data, and the entire method is highly transparent and clearly documented. The database has already been widely used, particularly in studies of globalisation (Los et al., 2015, Timmer et al., 2014). In addition to the normal current-price tables, WIOD include previous-year price tables, allowing improvements in some analyses (volume rather than value). WIOD's transparency and availability makes it popular in research and policy circles (Giljum et al., 2013). The WIOD team are applying for new funding to update the dataset (pers. comm.).

Eora: The Eora MRIO database was developed by the University of Sydney following world-leading research into the nature and means of balance in input-output tables (Lenzen et al.,2012a), and made publically available in 2012. Eora is the most detailed and therefore largest MRIO currently available, with the current version including 187 individual countries and a total of 15909 sectors (i.e., an average of 85 sectors per country, but the resolution varies from one country to the next). Recognising the size of the dataset, and the requirement for significant computing power to utilise it, Eora has also been released as a (preliminary) low-resolution version with 26 sectors per country. While there is a very high level of data disaggregation, caution is necessary because of the automated methods used to generate these data. IOTs for 113 of the 187 countries were automatically generated using aggregated statistics and representative tables of other countries. IOTs that are not automatically generated are sourced from official statistics agencies. Updates have been sporadic, without major version releases, and documentation is spread across several research articles. It is unclear what continued funding Eora has access to.

EXIOBASE: EXIOBASE was first released in 2012, as the main output of the EU-funded EXIOPOL project. That first database contained data only for the year 2000. A second version was released in 2015 as a result of the follow-up EU-funded project CREEA, with data for 2007. More recently, the DESIRE (Development of a System of Indicators for a Resource Efficient Europe) project concluded in early 2016 and version 3 of EXIOBASE is expected to be released this year. This latest version should present a time series of 1995-2011 in addition to "now-cast" data up to 2015. The focus of these databases has always been on resource efficiency, but their use is by no means restricted to that research area.

OECD: In 2015, the OECD released an MRIO called the OECD-ICIO, which includes all 34 OECD countries plus 27 other major economies, with 34 sectors in each country (Wiebe and Yamano, 2015). This is 
currently the only MRIO to include the important distinction of export processing (in China and Mexico). It is called an ICIO (inter-country IO table) because of the use of additional data to further constrain the bilateral trade data, with the intention of further improving these intercountry data in later releases. The database has been generated for the period 1995-2011, but some years are not yet publicly available. The work is a part of a joint OECD-WTO initiative, the OECD-WTO database on Trade in Value Added (TiVA). For environmental accounts, the OECD currently includes $\mathrm{CO}_{2}$ data. The dataset is not yet publically available due to confidentiality concerns from some nations.

GTAP-MRIO: The GTAP-MRIO is a different class of database, because the constructed table is not publically available, but rather the individual country input-tables are available, pre-harmonised, from GTAP (the Global Trade Analysis Project, at Purdue University, USA) for a charge. The methods have been described for constructing an MRIOT from these data (Peters et al., 2011a). The database has a long history, with the first version released in 1993, with new versions every 3-4 years. The number of countries has gradually increased to the current 120 plus 20 regions to represent the global economy at 57 sectors. The database is not available as an annual time-series, but an approximation method has been developed (Peters et al., 2011b). The first report (in French) of using GTAP to construct an MRIO was by Daudin et al. (2006), and later, Peters and Hertwich (2008a) independently constructed an MRIO shortly afterwards. Because the starting point has been the harmonised national IO tables available from GTAP, there is opportunity for independent teams to develop competing MRIO construction methods. For example, Tsigas et al. (2012) produced an inter-country IO table using additional trade data, including processing trade for Mexico and China, by incorporating pre-existing disaggregated tables for these two countries from two separate sources. In the harmonisation process, GTAP prioritises single-source macroeconomic, international trade and energy data over the submitted input-output tables. In addition, GTAP works with locals to generate IO tables for countries not already present in the database, making no attempt to automatically generate country tables. GTAP has a large research community, being one of the largest economic modelling datasets worldwide, and funding is secured based on subscriptions that give access to both the data and models.

Several other MRIO databases have been developed, although none of these are currently suitable for use in environmental footprint analysis. We describe these briefly for completeness: 
- The Japanese agency IDE-JETRO (Institute of Developing Economies, Japan External Trade Organization) has a very long history of developing MRIO tables, beginning in the 1960s and continuing today, although their tables have always been limited to a small number of regions (without global coverage), and the most recent is for 2005, covering only East-Asian countries (Meng et al., 2012).

- Yokohama National University in Japan have developed a Global InputOutput table (YNU-GIO; not strictly an MRIO because some countries are exogenous), derived from OECD's national IO tables (unrelated to OECD-ICIO, described earlier), for the period 1997-2012 (Sato and Shrestha, 2014).

- Eurostat's eeSUIOT is a sub-product of the EXIOBASE projects, covering only the EU, profiting from access to better data available within Eurostat.

- The Asian Development Bank has constructed ADB-MRIO, derived from WIOD with the addition of five further Asian countries (Bangladesh, Malaysia, Philippines, Thailand, Vietnam) for 2005, 2006, 2010, 2011.

\section{Pre-calculated consumption footprint results}

Several of the databases (e.g., Eora) provide pre-calculated results. These are a major benefit to stakeholders, as they can obtain a quick overview of a range of environmental footprints for numerous countries. We have discovered, however, that the off-the-shelf results can hide considerable uncertainties, and can contain errors. Thus, we urge caution with using off-the-shelf results.

\section{Discussion}

While only a few years ago there was only one MRIO available (GTAP), now there are five parallel endeavours. Each of the currently available MRIO databases has its advantages and disadvantages, and it is not clear which should be recommended over the others. The nature of these comprehensive economic databases is that data are often in conflict and manipulations have to be made to achieve the balance required before analysis can begin. This implies that the most detailed datasets are not necessary the most accurate.

Even with careful attention to use of official national data, the balancing required means that domestic input-output structures and trade flows are modified such that the final MRIO database does not replicate the original input data. This is potentially a problem for countries reporting IOTs or trade data. Edens et al. (2015) found it 
necessary to modify WIOD to make the Netherlands match officially reported data for their official calculations of different footprints.

Some databases provide off-the-shelf results, but these should be viewed with caution. With pre-calculated results, a modicum of trust is placed in the user to read and understand all the conditions and caveats associated with the analysis. The quality of documentation varies considerably between the MRIO databases. Moreover, off-the-shelf results are often incorrectly viewed as superior because those results are taken from a "single" data source, hiding the fact that they were generated from a large number of disparate sources.

Ultimately, the user will need to decide which dataset is fit for purpose, and preferably, generating results for different datasets may increase trust. While off-the-shelf results are appealing, they should be viewed with caution.

\subsubsection{Aggregation of environmental accounts}

To make environmental accounts easier to process and understand, results are often aggregated. Aggregation could happen within an environmental account (e.g., adding multiple sectors together) or across environmental accounts (e.g., adding carbon dioxide and methane, or blue and green water).

Aggregation within an environmental account is usually straightforward, as it is simply the addition of different sectors in the same quantities. Aggregation of results removes sector detail and decreases uncertainty (Karstensen et al., 2015b), but this may hide divergent and uncertain trends at a more detailed sector level. Aggregated input data can lead to "aggregation error" in the results, where the result differs from what would hypothetically be found by performing the calculation at a more detailed level. It is generally accepted that more detailed input data leads to more accurate results, but given that more detailed input data is often more uncertain, it is not clear what the optimal level of input data aggregation is.

Aggregation across environmental accounts is more complex, and often leads to the development of composite indicators, which can be formed by combining a set of separate indicators. While separate indicators provide useful, detailed information, a composite indicator potentially provides a concise summary that is more easily understood. Production of a composite indicator requires components expressed in different units to be "normalised" so that they may be combined. A well-known example is the use of 100-year global warming potential to combine the warming impacts 
of different greenhouse gases into a " $\mathrm{CO}_{2}$-equivalent". However, normalisation is subjective and requires assumptions and value judgements. In the case of global warming potential, the choice of impact factor (radiative forcing) and time horizon (usually 100 years) is critical to relative effects of each greenhouse gas (Myhre et al., 2013).

Reflecting the subjectivity in the production of a composite indicator, and also the potential for opaque development such that assumptions are hidden, Saisana and Tarantola (2002, pp. 13-14) list some disadvantages of using composite indicators:

- May send misleading policy messages if poorly constructed or misinterpreted.

- May invite simplistic policy conclusions.

- May be misused, e.g. to support a desired policy, if the construction process is not transparent and/or lacks sound statistical or conceptual principles.

- The selection of indicators and weights could be the subject of political dispute.

- May disguise problems in some dimensions and increase the difficulty of identifying proper remedial action, if the construction process is not transparent.

- May lead to inappropriate policies if dimensions of performance that are difficult to measure are ignored.

\subsection{Uncertainty}

To apply environmental footprints in policy, they need to be sufficiently accurate to support policy. While the literature on uncertainty has grown in recent years, it tends to focus on small elements of uncertainty and the uncertainty in environmental footprints has yet to be fully characterised. In line with the methods described in the previous section, uncertainties fall into three large areas (Figure 2): economic data, environmental data, and aggregation:

\footnotetext{
Environmental accounts: Territorial environmental accounts are the basis of environmental footprints, but the uncertainties are poorly characterised. There is currently very little information on the uncertainties in regional and global environmental datasets, particularly at the sector level, requiring analysts to make own estimates using disparate data (Karstensen et al., 2015b). Uncertainty information, if available, is usually for global totals or
} 
developed countries, and usually for air emissions and particularly greenhouse gas emissions only (European Commission, 2009, UNEP, 2012, Marland et al., 2009, Macknick, 2011).

Economic accounts: There is very little information available on the uncertainties in economic data. Combined with the complexity of constructing large MRIO systems, uncertainties are usually based on model comparisons or outcomes of matrix balancing (Karstensen et al., 2015b). Studies on the uncertainties generally lead to sweeping conclusions that uncertainties are manageable, seemingly contradicting significant differences at a more detailed and policy relevant sector level.

Aggregation: Aggregation can occur within or across environmental accounts. Aggregation within environmental accounts tends to reduce uncertainty, as errors tend to cancel with aggregation (Karstensen et al., 2015b). Aggregation across environmental accounts (composite indicators) increases uncertainty, as the weighting indices are themselves uncertain (Karstensen et al., 2015b). Particularly when aggregating across environmental accounts, the cancellation of errors that leads to a more stable net result could hide inherent uncertainties and policy relevant information.

Uncertainties can arise from both the method applied and the data used. We broadly discuss two main sources of uncertainty: Structural uncertainties indicate how models and data represent the real world; Parametric uncertainties arise from uncertainties in the input data that goes into the models (Peters et al., 2012).

\subsubsection{Limitations of input-output models}

IOA was originally developed and long considered for use in economic planning and scenario analysis, but has been superseded by the use of general equilibrium models. General equilibrium models have IOTs in their core but, critically, they allow economic structure to change with changes in supply and demand. This historical development has meant that many economists dismiss IOA as lacking usefulness, but this ignores the method's significant advantages in describing static economic patterns. These advantages have grown strongly with improvements to data, and are particularly relevant for environmental footprints.

The standard input-output model assumes that the inputs are proportional to outputs and these proportions are fixed (Leontief 1970). This means that irrespective of the size of the purchase, the supply chain will be identical. When dealing with average sector outputs and historic attribution, this linearity should have little impact on estimates of environmental footprints. If, however, modelling future environmental footprints in the response to policies, then this assumption would need to be relaxed. 
A disadvantage of input-output models is the high level of aggregation. While the most detailed country tables have 500 sectors, much more common is around 50-100 sectors. In contrast, life-cycle assessment databases can have thousands of products. However, the corresponding advantage of input-output models is that they are complete and cover the entire economy. Thus, completeness comes at the expense of detail. Depending on the policy question, IOTs may not have sufficient levels of detail, requiring the use of hybrid methods to increase detail.

Input-output models are generally measured in monetary flows, and it is assumed that the price of products is the same in each sector. In reality, it is known that different users can pay different costs (e.g., household versus industry purchases of electricity). One way around this is to use mixed-unit IOTs, where some data are presented in physical units (e.g., electricity). A disadvantage of physical units is that, within an aggregated sector, there is often a mix of units already and physical units may miss some value added from derivative products (e.g., non-electricity services supplied by the electricity sector).

IOTs implicitly assume that an industry produces one output. This assumption can be relaxed through the supply-use framework where each industry can produce multiple products. However, to use a supplyuse table for environmental footprint estimates requires making a "technology assumption" on joint production, which reduces the advantages of supply-use tables.

Overall, many of the assumptions of IOA have different relevance and consequences depending on the research or policy question. Environmental footprints are a very specific application of IOA, which attributes different economic activities to environmental flows. At the aggregated national level, many of the input-output assumptions become less relevant. As one presents more detailed sectoral results, some assumptions on joint production and linearity may become more important. To analyse the consequences of a past or future change in policy, many of the assumptions of IOA become problematic and need to be addressed by using a different modelling framework or adjusting the research question. Since input-output is a top-down approach (adds to the same global environmental flow), the various input-output assumptions ultimately mean that one sector or country will be allocated too much or too little environmental flow, with another sector or country compensating, leading to the same global total. 


\subsubsection{Structural uncertainties through model comparisons}

One method to assess uncertainties is to compare across independent environmental footprint estimates (Peters et al., 2012, Moran and Wood, 2014). For large countries (e.g., US, EU, China), the difference between independent estimates is moderate, but for smaller countries the differences can be significant. Additionally, the temporal trends from independent estimates are often the same, but in individual years, growth rates can be markedly different and even have different sign.

Figure 5-8 show a model comparison for the Nordic countries comparing three different datasets (GTAP-TSTRD, Eora, WIOD), as well as different methods for one dataset (GTAP). Differences already exist at the territorial level (production, top figures), see Section 2.2.1. The differences between Eora and GTAP essentially represent independent estimates from independent organisations, while WIOD is specifically allocated on a residence principle and therefore highlights the extent of international transportation (Denmark is a good example). The differences in production emissions then propagate through to the consumption emissions (middle plots).

The environmental footprint (consumption) in each region can be at different magnitude in different models, though trends are generally the same. In terms of absolute levels, the spread in production emissions from the three estimates is around $20 \%$ (Sweden), while the spread in consumption emissions is around 10\% (Sweden). For the three Nordic countries shown, the spread in the consumption estimates is no greater than the spread in the production estimates. This apparent contradiction occurs for other countries, and has never been adequately addressed. However, it may indicate that it is not the detailed structure of the IOT that drives the environmental footprints, but rather, key macroeconomic variables such as GDP, exports, and imports, and so on. This is an area that needs further research.

Broadly speaking, the emission transfer (production minus consumption) is similar in each of the datasets, with the exception of Norway and Denmark. For Denmark, if international transport is allocated to sectors (as in the residence principle), then Demark becomes a net exporter. Norway can appear as either a net exporter or net importer, depending on how well the oil and gas sector is represented. A greater uncertainty is expected for the emission transfer as it is the difference of two similarly large numbers. However, in many respects, the change in the net emission transfer may be the most policyrelevant indicator. 
Figure 5: Time series of $\mathrm{CO}_{2}$ emission estimates from different sources for Denmark. Note that the axes do not start at zero
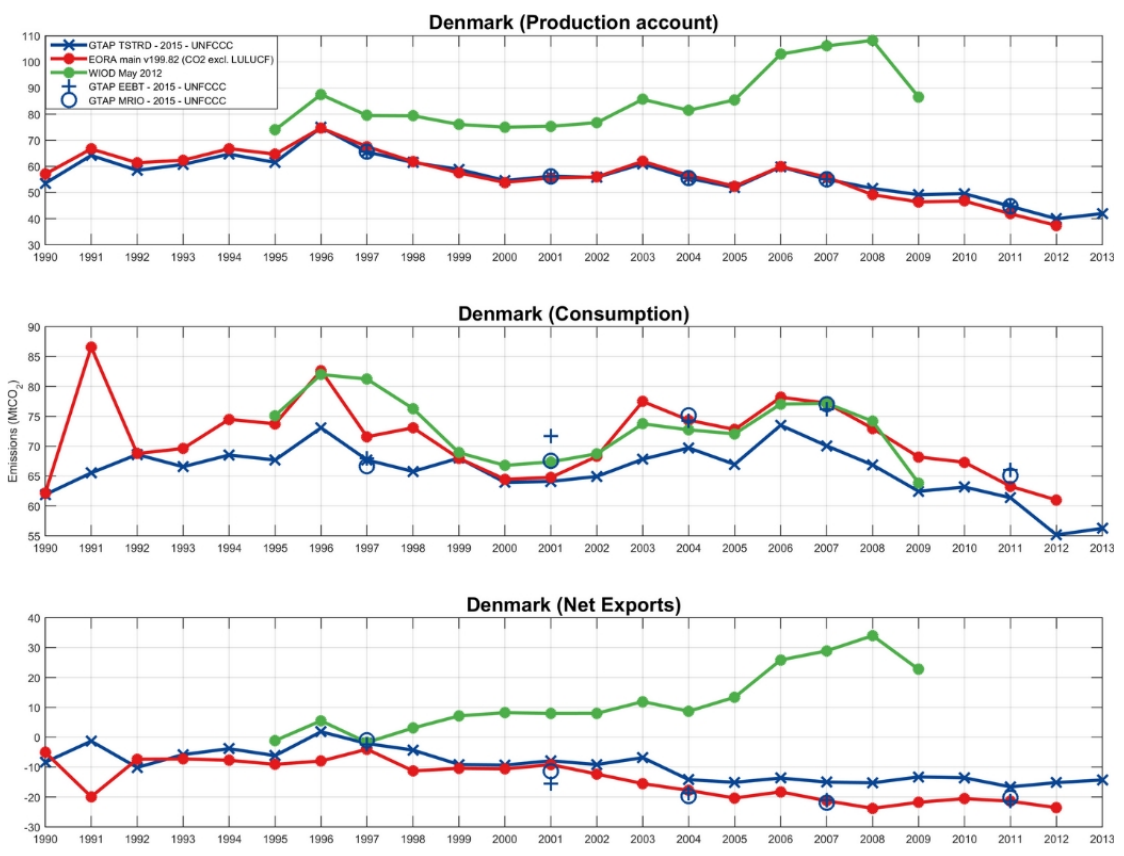

Source: GTAP-TSTRD/EEBT/MRIO (Le Quéré et al., 2015, Peters et al., 2011b), EORA, WIOD.

Figure 6: Time series of $\mathrm{CO}_{2}$ emission estimates from different sources for Finland. Note that the axes do not start at zero
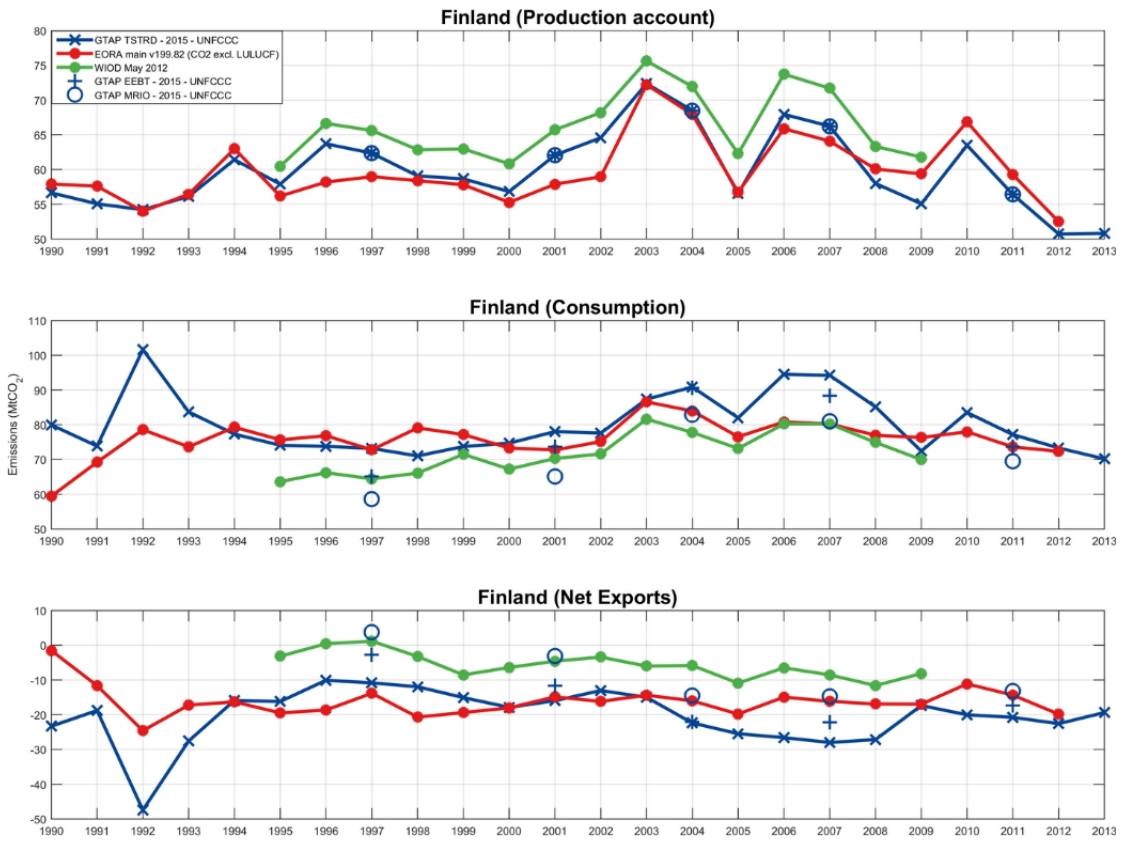

Source: GTAP-TSTRD/EEBT/MRIO (Le Quéré et al., 2015, Peters et al., 2011b), EORA, WIOD 
Figure 7: Time series of $\mathrm{CO}_{2}$ emission estimates from different sources for Norway. Note that the axes do not start at zero
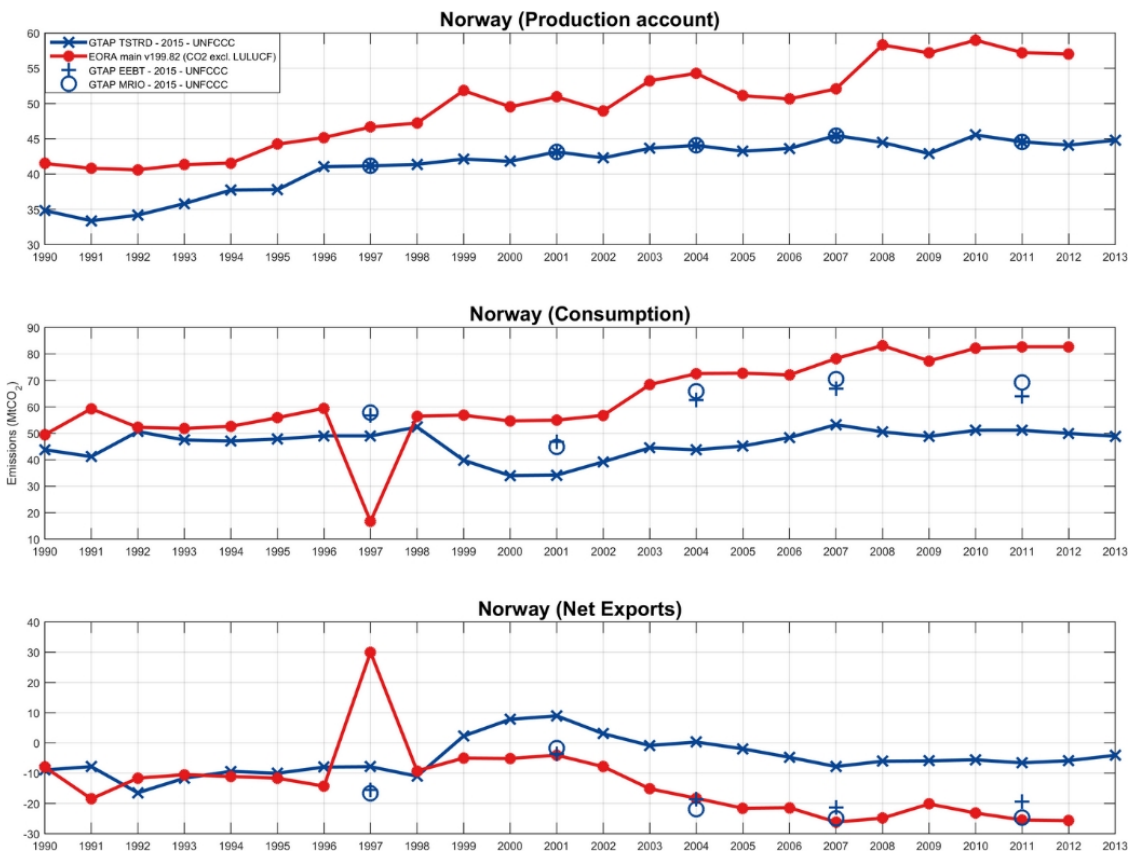

Figure 8: Time series of $\mathrm{CO}_{2}$ emission estimates from different sources for Sweden. Note that the axes do not start at zero
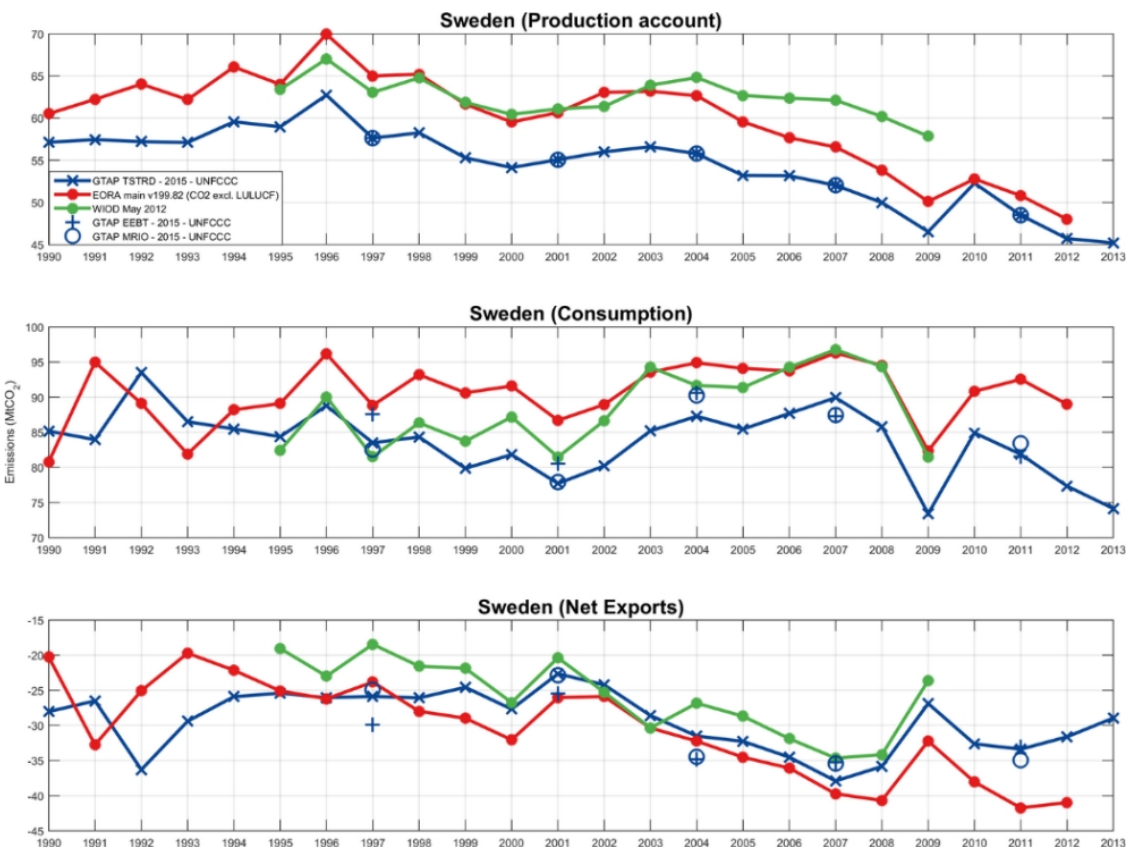

Source: GTAP-TSTRD/EEBT/MRIO (Le Quéré et al., 2015, Peters et al., 2011b), EORA, WIOD. 


\subsubsection{Parametric Uncertainties}

The environmental and economic accounts used to estimate environmental footprints contain large amounts of data. The final GTAP-MRIO used by CICERO has 140 regions, 57 sectors in each region, three final demands, and environmental accounts, and is based on about two million data points. Each of these data points has an unknown uncertainty distribution, and may correlate with other data points. Uncertainty information for this type of economic data only exists in very isolated cases, and analysts have to make extrapolations to perform uncertainty analysis.

It is common to assign uncertainties based on the size of the data point, assuming large values are more reliable and small values are less reliable in relative terms. It is, however, unclear how the underlying mechanisms for this uncertainty relationship work, as uncertainties may come from a combination of conflicting input data, unreliable measurements, bias in the source data, allocations and aggregations, base year extrapolations, estimates and assumptions, etc. (Wiedmann, 2009, Weber, 2008, Lenzen, 2000a). There is no data available on correlations between data sets (e.g., one would expect strong correlations between national IOTs and trade data, or national IOTs and energy accounts). Even when the most basic uncertainty information is collated, performing uncertainty analysis using error propagation requires significant computing resources.

Despite the challenges, there are several studies that have used Monte-Carlo error-propagation techniques with IOA (Lenzen et al., 2010, Wiedmann, 2009, Wiedmann et al., 2008, Lenzen, 2000b, Karstensen et al., 2015b). These studies generally find that the resulting errors are small, but this may be a consequence of uncertainties cancelling due to the large number of additions and multiplications (Peters, 2007). All studies find that uncertainties increase for more detailed results, and decrease with aggregation. Karstensen et al. (2015b) found little difference in uncertainties between territorial and consumption-based emission estimates, and this largely indicates that environmental footprints are dominated by territorial environmental accounts (i.e. the import and export components are generally small in comparison), and the additional uncertainty from the economic accounts is limited by cancellation effects. A weakness of all these studies, and the largest knowledge gap, is how these uncertainties may increase with the inclusion of correlations in the environmental and economic accounts. 


\section{The policy relevance and application of environmental footprints}

There is a range of different environmental issues addressed by environmental footprints, but the policy context can differ substantially between these. Greenhouse gas emissions lead to global climate impacts largely independent of where the emissions occur, and consequently a global policy response is most effective. In contrast, local water pollution covers a limited geographic extent, and policy measures to reduce local water pollution in distant lands may not be of policy interest. Policies addressing material, land, and water footprints may lead to better resource efficiency, and ensure the future supply of potentially scarce resources. Thus, policies and measures relevant for one environmental issue (e.g., climate change) may not be relevant for other policy domains (e.g., water use).

To make analysis of the potential policy context and policy instruments tractable, it is worth delineating policies that can be used in a domestic context and those that may be seen as "additional" when including imported flows from other countries. Policies that regulate private transportation or household energy consumption have little impact on international trade flows, and would be implemented regardless of whether a territorial or consumption (footprint) system boundary was used for policy. Border carbon adjustments to improve the economic efficiency and environmental effectiveness of unilateral climate policies effectively change international trade flows, and thus directly affect the international component of an environmental footprint. Even though a policy on domestic transportation and a border carbon adjustment may both reduce an environmental footprint, we focus here only on the policy domain that is "additional" when switching from a territorial to footprint perspective (that is, policies that address imported flows from other countries).

In this chapter, we discuss the policy context for different environmental footprints, before discussing the policy relevance to the international dimension of environmental footprints. We discuss carbon 
footprints, land and water footprints, and material footprints in dedicated sections.

\subsection{Carbon and greenhouse gas footprints}

A "carbon footprint" has become a common phrase, but the term has multiple meanings that may fit different applications. The term "carbon footprint" is also often misused, particularly in the media, to refer to territorial carbon emissions. Further, it is often ambiguous whether a "carbon footprint" refers only to carbon emissions or to all greenhouse gas emissions weighted to a $\mathrm{CO}_{2}$-equivalent scale (using, for example, a Global Warming Potential), implying the need for clear description whenever footprints are published.

Here, we use the term carbon footprint to refer to emissions occurring in all countries that are allocated to national consumption of goods and services. We use carbon footprint to refer to either carbon dioxide or all greenhouse gas emissions, relying on context to clarify. If a carbon footprint includes all greenhouse gas emissions, the policy context is much the same, but there is a shift in emphasis towards food and agriculture.

\subsubsection{Policy context}

Most greenhouse gas (GHG) emissions cause the same climate impact regardless of where the emissions physically occur, consequently a global policy approach is needed (Kolstad et al., 2014). Policy makers generally regulate the GHG emissions over which they have jurisdiction, leading to the use of territorial emission accounts in climate policy (Peters et al., 2009). Since in the United Nations Framework Convention on Climate Change (UNFCCC) and its Kyoto Protocol applies "common but differentiated responsibilities and respective capabilities", climate policies are most prominent in developed countries. Since the developed countries represent a decreasing share of global emissions, climate policies have had limited effect in reducing the growth in global emissions. Combining this with the rapid growth in international trade, there is concern that "carbon leakage" may have undermined climate policies. This has motivated the study of consumption-based emissions (carbon footprints) in climate policy, with the initial motivation to assess the extent of "carbon leakage" (Wyckoff and Roop, 1994, Munksgaard and Pedersen, 2001, Ahmad and Wyckoff, 2003). 
Empirical studies of historical consumption-based emissions have found that developed nations collectively have higher consumption-based emissions than territorial-based emissions, meaning that they are net importers of emissions (Peters et al., 2011b, Le Quéré et al., 2015). The increase in consumption-based emissions over territorial-based emissions in developed countries (taken here as Annex B countries in the Kyoto Protocol) has grown $1.1 \mathrm{GtCO}_{2}$ from 1990 to 2013 (with a maximum of 1.5 $\mathrm{GtCO}_{2}$ in 2007), about the same size as the territorial emission reduction in Annex B countries over the same period $\left(1.4 \mathrm{GtCO}_{2}\right)$. However, after strong growth between 2002 and 2007, the gap between production and consumption (net emission transfers) has since stabilised. China has driven most of the changes in net emission transfers over time, including the recent slowdown (Le Quéré et al., 2015). The difference between territorial- and consumption-based emissions has been termed "net emission transfers" (Peters et al., 2011b), "weak carbon leakage", and "consumption-induced carbon leakage" (Peters, 2010b).

The trends in consumption-based and territorial-based emissions in individual counties can differ from the aggregated trends in developed countries. Figure 9 shows the carbon footprint $\left(\mathrm{CO}_{2}\right.$ only) for the Nordic countries and the EU28 (Le Quéré et al., 2015). The Nordic and EU countries show different trends compared to the aggregate of all developed countries. On balance, the Nordic and EU28 countries are net importers of $\mathrm{CO}_{2}$ emissions (consumption emissions are higher than the territorial emissions), and the net import has remained approximately constant since 1990. In the early 1990's there was a slight decrease in the net imports, primarily due to the collapse of the Former Soviet Union, particularly notable in Finland. Since around 2000, there has been an increase in the net import, largely due to imports from China, which is a pattern seen in most countries (Peters et al., 2011b). From around 2005-2010, the net imports have stabilised, reflecting a slowdown in the growth of exported emission from China. Since around 2005, both consumption and territorial emissions have fallen in the Nordic and EU28 counties.

The individual Nordic countries can have different trends, representing different national circumstances. For Denmark, Finland, and Sweden, about $50 \%$ of their consumption-based emissions originates in another country. The imported emissions have generally grown over time, but have stabilised in recent years and in some cases decreased. Norway has a slightly different trend, in additional to poor data quality before 2000 in the GTAP database we use. Norway has a large share of emissions from the production of exported products, primarily due to emissions from oil and gas extraction. The exported emissions roughly 
balance with the imported emissions, making the territorial and consumption emissions in Norway similar in magnitude.

Figure 9: Time series of $\mathrm{CO}_{2}$ embodied in production, consumption, exports and imports
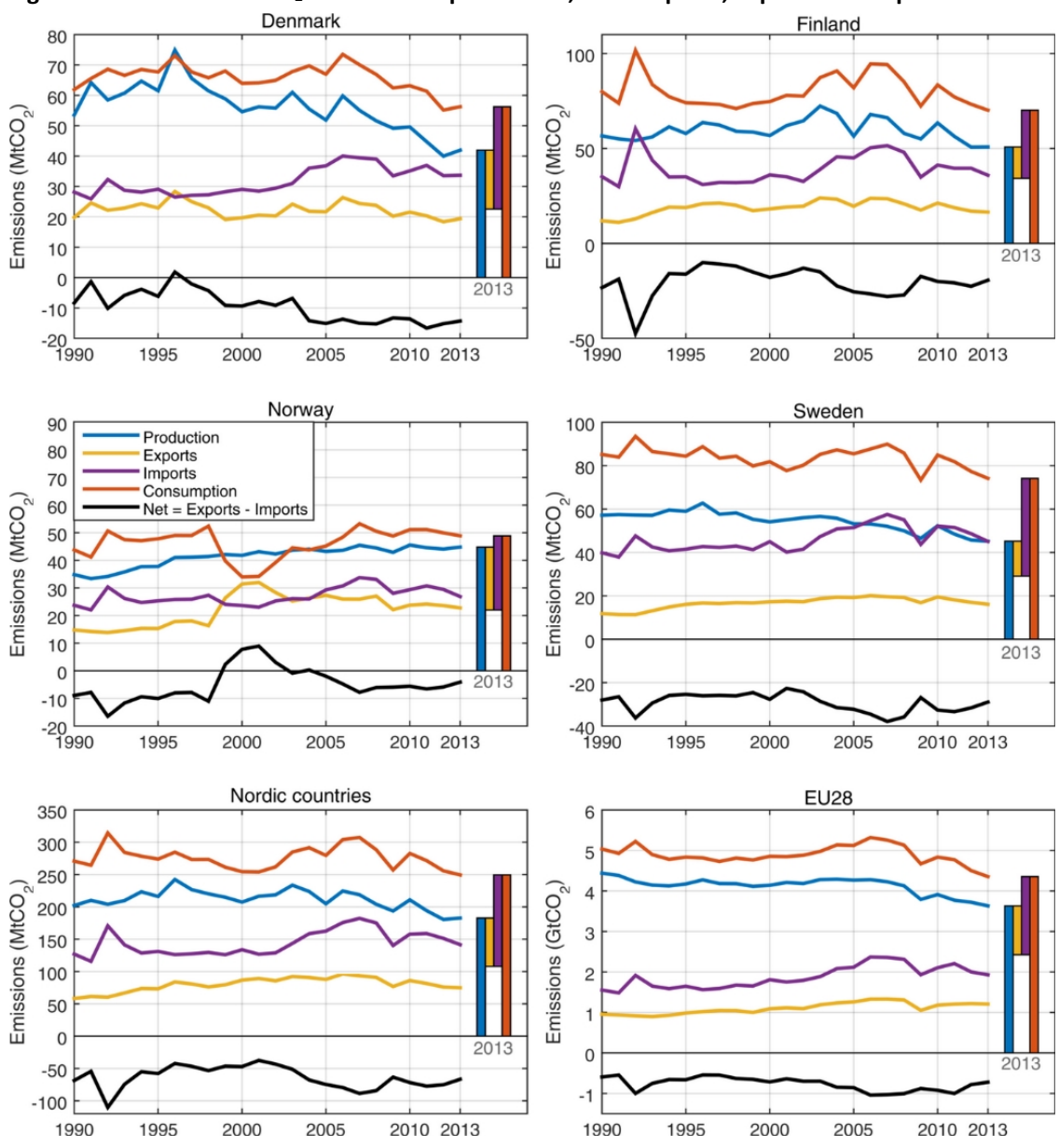

Source: GTAP-TSTRD with UNFCCC (Le Quéré et al., 2015).

An important feature of consumption-based emissions is that they provide complementary information on the consumption patterns that lead to emissions (Karstensen et al., 2015a). From a territorial perspective, emissions occur in electricity production, transportation, agriculture, and energy-intensive manufacturing. Shifting to a consumption perspective, Figure 10 shifts the emissions to services, consumer products (non-energy intensive manufacturing), construction, and food. Most electricity is transferred to services, manufacturing, and construction. There are large flows from agriculture to processed food, and from energy intensive manufacturing to manufacturing and construction. A sector perspective shifts the focus 
from producing to consuming sectors and may lead to alternative policy instruments, such as those focussing on consumption rather than production (Karstensen et al., 2015a, Hertwich and Peters, 2009).

Figure 10: Production (Prod) and consumption (Cons) $\mathrm{CO}_{2}$ emissions of the Nordic countries broken down by emitting and selling sectors. Countries aggregated as Nordic countries are Norway, Denmark, Finland and Sweden. NEIM: non-energy-intensive manufacturing; EIM: energyintensive manufacturing
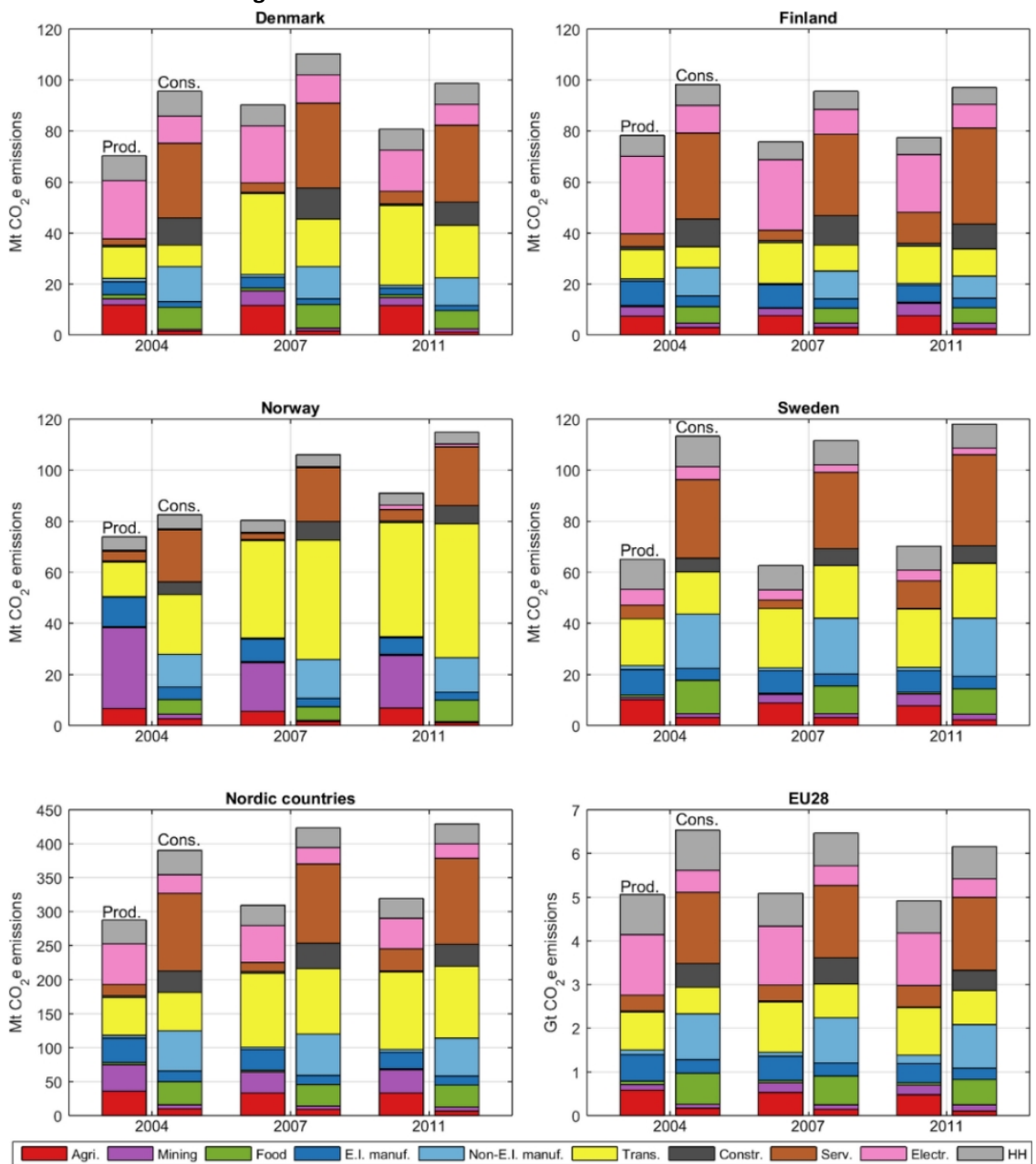

Source: GTAP-MRIO, own calculations.

\subsubsection{Policies}

Countries have followed the standard textbook response to climate policy and implemented domestic policies, such as market-based instruments (e.g., carbon pricing, emissions trading), and regulations (e.g., energy efficiency, renewable energy targets, information programmes). Most 
climate policies have been implemented in developed countries, but developed countries are unwilling to unilaterally deepen their climate policies. The main fear is that unilateral climate policies will lead to competitive disadvantage, causing certain industries to lose market share to unregulated (developing) countries. This, in turn, may lead to "carbon leakage" since production and emissions in unregulated countries increases, while at the same time decreasing in regulated countries.

The standard textbook response to the fragmented implementation of production-based climate policies is to increase the number of countries with effective domestic climate polices through negotiations. This has partly been achieved in the Paris Agreement, where all countries have pledged to limit emissions but it is still expected that developed countries have deeper limitations consistent with "common but differentiated responsibilities and respective capabilities". The emission pledges, when supported by new policies, are unlikely to lead to globally uniform climate polices. The challenge of fragmented climate policies are likely to persist into the future, but to a lesser degree than in the Kyoto Protocol.

Due to the continued challenge of fragmented climate policies, analysts have suggested incorporating "second best" approaches (Lipsey and Lancaster, 1956). In recent years, there has been growing focus on consumption-based policy instruments as a complement to the existing production-based ones (Peters and Hertwich, 2008b, Barrett et al., 2013, Springmann, 2014). Policy instruments include, but are not limited to, the use of consumption-based emission limitations (Munksgaard and Pedersen, 2001), trade measures (Markusen, 1975, Hoel, 1996), targeted financial transfers (Springmann, 2014), or policies directed at consumers (Tukker et al., 2010). Consumption-based policy instruments are more complex than production-based policy instruments (Peters, 2008, Peters and Hertwich, 2008b), and since they give different incentives for mitigation they may lead to new political divisions (Victor et al., 2014). It is unclear whether consumption-based approaches would improve existing policies enough to justify the added technical and political complexity.

We now discuss several consumption-based policy instruments that may help improve the economic efficiency and environmental effectiveness of unilateral climate policies.

\section{Consumption-based emission limitations}

Perhaps the most "obvious" way to implement a consumption-based policy is to allocate emissions to countries based on their carbon footprint. A net importer (e.g., the Nordics) would be allocated more emissions, while a net exporter (e.g., China) would be allocated less emissions. However, implementing such a policy is not straightforward. 
Since a carbon footprint is used, a part of the emissions occur outside of the regulated country where there is no jurisdiction to regulate emissions. Hence, a mechanism would be needed to achieve emission reductions in the external country.

An alternative approach is to give countries a different emission reduction based on the share of imported emissions, potentially along with other burden-sharing approaches. In this case, a net importer (e.g. the Nordics) would reduce their emissions by a greater percentage due to their net import, while a net exporter (e.g., China) would reduce their emissions by a smaller percentage or not reduce emissions at all. Springmann (2014) found that such a policy was the least preferable out of several consumption-based policies. This is because it increases the costs on the regulating countries and thereby reduces economic activity, and this has negative repercussions for the unregulated region

\section{Border Carbon Adjustment (BCA)}

Research initiated in the 1970's showed that Border Carbon Adjustments placing an equivalent carbon price on imports and rebating the price paid for exports - could improve the economic efficiency and environmental effectiveness of unilateral policies (Markusen, 1975, Hoel, 1996, Felder and Rutherford, 1993). This earlier research has motivated a political discourse on BCAs and a large literature, particularly exploring the economic implications and effectiveness of BCAs (Böhringer et al., 2012a).

BCAs are implemented to address "policy-induced carbon leakage", carbon leakage caused by climate policy itself. This is distinct from "consumption-induced carbon leakage" (Peters, 2010b), which is caused by a changing global division of labour particularly due to the emergence of China since the 2000's. Policy-induced carbon leakage is a subset of the much larger consumption-induced carbon leakage. BCAs are expected to reduce policy-induced carbon leakage, but may have an indirect effect on consumption-induced carbon leakage.

BCAs have been, the most studied consumption-based policy instrument. Generally, it is found that they lead to only modest improvements in environmental effectiveness and economic efficiency, and have a variety of equity and legal challenges. Given these challenges, and the broad support for the Paris Agreement, it is perhaps unlikely that BCAs will be implemented in the future. Nevertheless, we summarise some of the advantages and disadvantages.

Environmental effectiveness: Modelling studies have found that BCAs are effective at reducing policy-induced carbon leakage, but the gains are relatively small. The average multi-model carbon leakage rate (increased emissions in non-regulated countries versus decreased emissions in 
regulated countries) is reduced from $12 \%$ to $8 \%$ for a $20 \%$ unilateral reduction in emissions in developed countries (Böhringer et al., 2012a). The effectiveness of a BCA to reduce carbon leakage is found to be higher, when industrial process emissions are included (Bednar-Friedl et al., 2012). Theoretical results from stylised models have suggested that a BCA could increase global emissions (Jakob et al., 2013), but this is not currently supported by quantitative modelling evidence (Böhringer et al., 2012a, Weitzel et al., 2012).

Economic efficiency. BCAs may improve economic efficiency by achieving a given emission reduction at lower global cost (Steininger et al., 2014, Fischer and Fox, 2012), though modelling shows that the global cost reductions from using a BCA are only modest (Springmann, 2014, Böhringer et al., 2012a). A multi-model comparison found that the use of a BCA reduces the GDP loss of a reference climate policy by $8.5 \%$ (model mean) for a global 20\% emission reduction (Böhringer et al., 2012a).

Equity. Despite modest improvements in effectiveness and efficiency, BCAs exacerbate existing inequalities (Böhringer et al., 2012a) raising concerns about coherence with other policy goals (Steininger et al., 2014). Unilateral climate policy by industrialized countries shifts the terms-oftrade in their favour, an effect that is exacerbated by BCAs (Böhringer et al., 2012b, Böhringer et al., 2012a). Inequalities can be reduced if financial transfers are used as an offset (Springmann, 2014, Böhringer et al., 2012b).

Legal and political issues. BCAs place a barrier on imports, and this is a specific challenge from a legal and political point of view (Horn and Mavroidis, 2010) and be considered a disguised form of protectionism (Cosbey et al., 2012). According to the basic principles of the World Trade Organization (WTO), a product that is traded between WTO member states must not be discriminated against at the border based on its origin or based on the way it had been produced. A BCA can be in accordance with WTO rules (GATT Article III), but the design of the BCA is critical (Pauwlyn, 2012, Horn and Mavroidis, 2010). Even if the design of a BCA does not match the basic rules for non-discrimination, it can be subject to exemptions stipulated in GATT Article XX. On balance, a BCA may be able to navigate through the WTO, but it will face close scrutiny and likely be politically unpopular given the progress in climate policy under the Paris Agreement.

\section{Financial and technology transfers}

The main challenge with consumption-based policies is that they require the regulating country to reduce emissions in a country where they do not have jurisdiction (e.g., Norway does not have jurisdiction to reduce emissions in China). The root cause of the imported emissions may be mainly due to technologies in the unregulated country (e.g., coal use in 
electricity production), not necessarily international trade or consumption. An effective method to reduce imported emissions is therefore to help improve technologies through financial and technology transfers in some proportion of the imported emissions (Reinvang and Peters, 2008). This is in the spirit of the Clean Development Mechanism and is based on the premise that emissions reductions are more costeffective in developing countries. Springmann (2014) finds that this policy yields the largest net benefits among different consumption-based policies, and is the most cost-effective in reducing global emissions. While financial and technology transfers are generally not seen as consumptionbased policies, they may be the most promising policy instrument to improve the effectiveness and efficiency of unilateral climate polices.

\section{Consumer policies}

A range of policy instruments may use consumption-based emissions to influence consumer behaviour, such as, labelling, information programmes, standards, nudges, mandatory reporting, and similar (Tukker et al., 2010, Hertwich, 2011). The focus of such measures is usually on consumers, either private consumers or industry consumers. While the focus of many of these measures may be to reduce carbon footprints by reducing or shifting consumption, many of the measures may not have noticeable effects on the imported component of a carbon footprint.

There is little empirical analysis, particularly at the macro level, on the effectiveness of these policy instruments affecting individual and collective behaviour sufficiently to reduce carbon footprints (Dietz et al., 2009), particularly if rebound effects are included (Gillingham et al., 2013, Hertwich, 2005). As examples, product labelling appears to have little effect (Beattie, 2012) and information programmes often have to be bundled with other incentives to obtain synergistic effects (Dietz et al., 2009). The generally low level of effectiveness of these consumerfocussed policy instruments can be explained by the fact that environmentally-friendly behaviour is often hindered by multiple personal (lack of information, beliefs, social norms) and contextual (e.g. financial aspects, inconvenience, time constraints) obstacles that are specific to an individual and situation (Stern, 1999, Steg and Vlek, 2009). However, many consumer interventions can be implemented quickly and at a relatively low cost (Vandenberg et al. 2008). 


\subsection{Land and water footprints}

We have grouped land and water footprints together as they have similar drivers and policy relevance. Both land and water footprints are largely (not exclusively) driven by agricultural production, and policies on land or water footprints may have significant overlaps.

While the carbon and land footprint concepts have no single standards associated with them, the water footprint has clearly defined methodologies with the Water Footprint Network. This aims to maintain established definitions, and arguably, prevent alternatives from appearing. This standardisation effort perhaps stifles the normal evolutionary nature of science and prevents development and reevaluation of concepts and ideas to accept valid counter-arguments.

\subsubsection{Policy context}

\section{Water Footprint}

The water footprint concept developed out of the earlier idea of virtual water, introduced by Tony Allan in studying the political consequences of water deficits of the Middle East and northern Africa (Allen, 1992). This subsequently developed into the water footprint, which was introduced at about the same time as the carbon footprint, in the early 2000's (Ercin and Hoekstra, 2012), although these strands of research were independent of each other. The water footprint was modelled on the ecological footprint (Hoekstra et al., 2011), essentially as a measure of "sustainability", particularly to assess whether the water footprint can be reduced - independent of the geographic context - at acceptable social costs.

The water footprint is the total supply-chain water use associated with a product (group of products/consumers or region), disaggregated into blue, green, and grey water, and preferably indicating when and where the water was used (Hoekstra et al., 2011). Blue, green and grey water refer to different water flows:

- Green water footprint is water from precipitation that is stored in the root zone of the soil and evaporated, transpired or incorporated by plants. It is particularly relevant for agricultural, horticultural and forestry products.

- Blue water footprint is water that has been sourced from surface or groundwater resources and is either evaporated, incorporated into a product or taken from one body of water and returned to another, or 
returned at a different time. Irrigated agriculture, industry and domestic water use can each have a blue water footprint.

- Grey water footprint is the amount of fresh water required to assimilate pollutants to meet specific water quality standards. The grey water footprint considers point-source pollution discharged to a freshwater resource directly through a pipe or indirectly through runoff or leaching from the soil, impervious surfaces, or other diffuse sources.

The rationale for a water footprint is to quantify the amount of water used by different processes or activities, and ultimately, reduce the water footprint. A key concern with the water footprint is that it is for a renewable resource, water is not destroyed, and therefore a higher footprint in no way guarantees greater unwanted environmental or economic impact (Smil, 2008). The problem is when water is overused: consumption beyond some level that would allow sufficient availability for other purposes, whatever they might be. Whether or not water use is below this threshold depends on the water availability and other demands at the specific location and time where the water is used, i.e., on some estimate of water scarcity (Feng et al., 2014). Lenzen et al. (2013) attempted to estimate national water footprint accounts with water scarcity factored in. While this is a step in the right direction, the problem is largely unresolved by this effort. In their words: "We do not determine water stress or water scarcity as a result of our calculations" (p80). In fact, what they do is to weight water use by an indicator of water scarcity, at the national level.

There have been a variety of criticisms of water footprints. Wichelns (2010) argues that water footprints are only relevant if scarcity is included, and further in Wichelns (2011) that the "assessment of blue, green, and grey water footprints will not enhance understanding of water resource issues or contribute in meaningful ways to the improvements in water management that are needed to alleviate poverty and ensure food security". The water footprint is a measure of water use, but there are a multitude of definitions that may not be accepted or relevant to policy makers. For example, blue water consumption relates to the "consumptive" use of water, including evaporation, incorporated in a product, transferred to another basin, and a delay in return flow. Not all these aspects may be relevant. For example, the delay in the return flow could elevate the footprint (e.g., extensive use of hydropower), but policies may not be able to or willing to avoid this. Further, water can be reused at a later time (Smil, 2008), and this can be lost in an aggregated water footprint. A policy maker may want a specific definition of the 
water footprint to overlap with the area that they have policy control or interest. These criticisms do not necessarily render the water footprint concept "useless". Wichelns (2010) argues that water footprints are helpful in starting policy discourse, but that the public policy value is limited due to conceptual limitations and the important role of other factors in determining optimal resource allocation.

\section{Land Footprint}

The land footprint has a long history, probably first used conceptually by Borgström (1965) and then popularised with the ecological footprint (Wackernagel and Rees, 1996) which can be seen as a type of land footprint. Today, the land footprint is generally defined as the total land area that is used, directly and indirectly, associated to a given product, (economic) activity or final consumption. Land areas are often disaggregated into cropland, pastures, and forest areas. The land footprint measures actual land use, and conceptually differs to the approach taken in the ecological footprint which weights land to a global average productivity measured in global hectares (Wiedmann and Lenzen, 2007).

In comparison to carbon and water footprints, there is a much smaller literature on actual land use. Most studies, apply similar approaches to the ecological footprint by converting actual land into a "global hectare" (Weinzettel et al., 2013, Steen-Olsen et al., 2012). There does not exist any organisation such as the Ecological Footprint Network or Water Footprint Network that promotes the use of particular land use indicators. There has been criticism of the ecological footprint approach to land accounting (Wiedmann and Lenzen, 2007, van den Bergh and Grazi, 2014, van den Bergh and Verbruggen, 1999), but very few studies have been done on direct land use at the national level (Cuypers et al., 2013, Wilting and Vringer, 2009).

As for the water footprint, one could similarly criticise a land footprint. It is likely that society will always use land, so the policy question is not really about the amount of land-use, but rather the quality of the land and degradation. The policy question then becomes very local and region-specific, with the exception of land-use change which can lead to greenhouse gas emissions, biodiversity loss, etc. Since land and water use will generally be co-located there is likely to be a range of synergies in working with the two. 


\section{Land and Water Footprints}

Here we use WIOD to show land area and water footprints (Figure 11). As mentioned earlier, WIOD only includes data for the three EU-member Nordic countries. The territorial land and water use in the Denmark, Finland, and Sweden has been relatively constant over the 1995-2009 period. The variations in the Swedish territorial land use 2005-2007 are most likely data errors. While the WIOD data are ultimately sourced from FAO, we have experienced significant land-area issues in FAO data previously (Andrew and Forgie, 2011). In terms of the footprints (consumption), the land and blue water footprints are relatively constant, and territorial land and blue water use is very similar to the footprints. Denmark, Finland, and Sweden are net importers of green and grey water, and these are increasing over time.

Figure 12 shows more detailed sector results in the years 1995, 2000, and 2008. The land accounts are only allocated to agricultural sectors, but are consumed in a variety of final consumption sectors (agriculture, food, and services). Blue water accounts are primarily allocated to electricity production, but for final consumption direct electricity consumption and services dominate. Green water accounts are allocated to agriculture only, and as for land, reallocated primarily to agriculture, food, and services for final consumption. Grey water accounts are primarily allocated to agriculture and heavy industry, with agriculture, food, light manufacturing, and services dominating final consumption. The increase in the green and grey water footprints over times seems to be due to greater consumption (and trade) in food, light manufacturing, and services. 
Figure 11: The land and water footprints for the Nordic countries with sufficient data (Denmark, Finland, and Sweden)
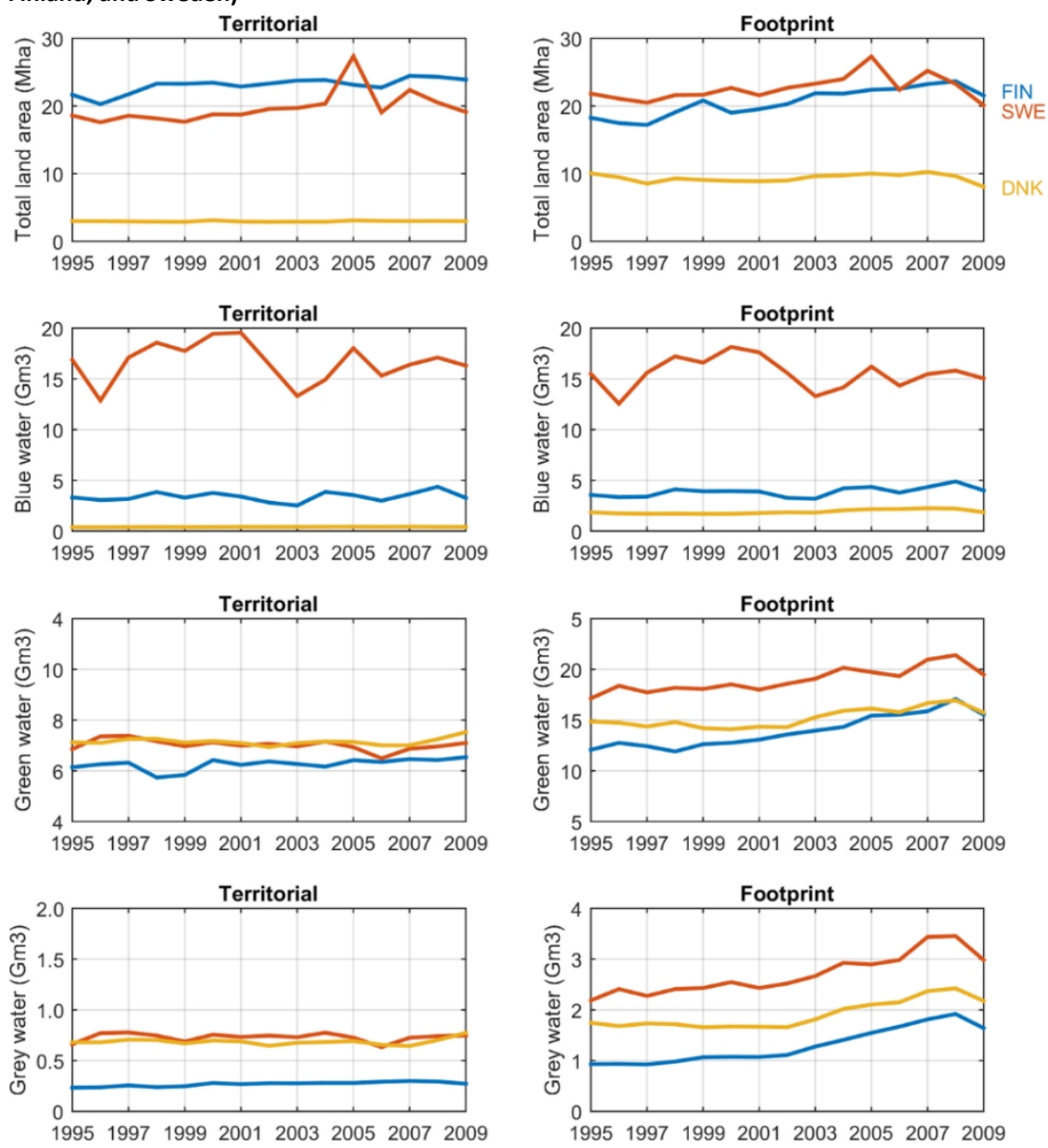

Source: WIOD, own calculations. 
Figure 12: The land and water footprints for the Nordic countries with sufficient data (Denmark Finland, and Sweden) showing the sector detail in the years 1995, 2000, 2008
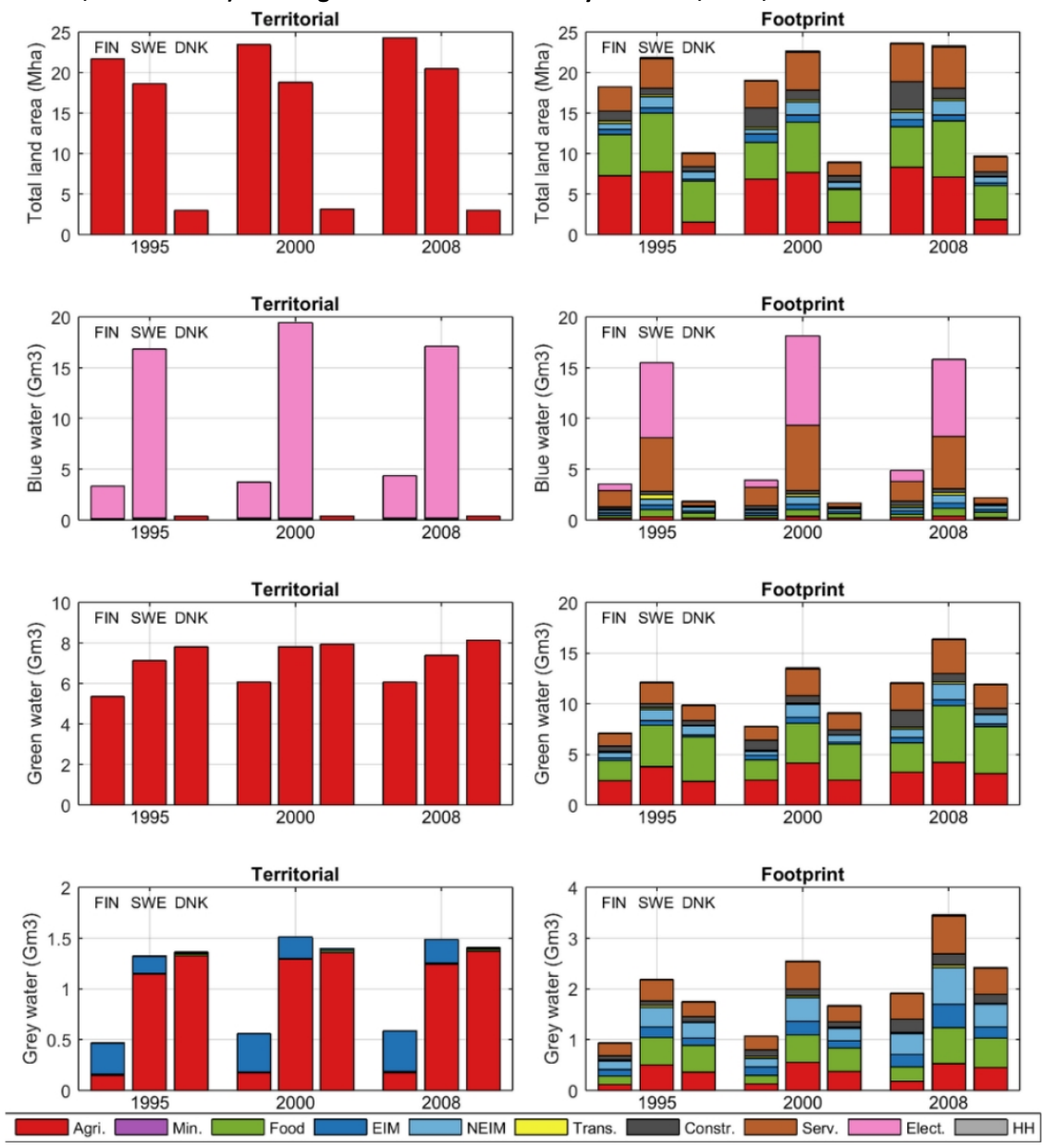

Source: WIOD, own calculations

\subsubsection{Policies}

Water and land footprints suffer essentially the same core limitation as carbon footprints: an extensive literature on estimating footprints, but an immature literature on policy application. One important difference between carbon and land/water footprints is that, with the urgency of climate change and insufficient action so far, any carbon emissions are unwanted: We now desire net-zero or even net-negative carbon emissions (Clarke et al., 2014). In contrast, land and water use are a requirement for human and ecosystem existence, and a great deal of land and water use is not harmful at all (Wichelns, 2011). Further, while 
growth in energy consumption and carbon emissions has been rapid and resource limits are still a long way off, land and water use is physically constrained (Cuypers et al., 2013); land and water policy is about sharing the available resource sustainably as opposed to reducing use to zero. This again comes to the point that land and water use, per se, are too far removed from the undesirable impacts that we wish to mitigate, which relate more to water and land scarcity and pollution (Wichelns, 2010). Unlike carbon, it is probably not possible to assign global sustainable limits on water or land use, although it may be possible at the basin level (Hoekstra et al., 2011).

International trade does not directly influence land and water scarcity, but land and water scarcity can influence trade (Antonelli and Sartori, 2015). Countries that have insufficient land or water have to rely on the import of (primarily) food products. Further, to meet the tastes of consumers, countries trade different types of food products (e.g., Norway exporting cod to Spain, but importing tomatoes back). Thus, water-rich countries (e.g., Norway) can be importers of food because of land (and growing season) limitations, to obtain diversity in food, or to improve terms of trade. Similar issues hold for land-rich countries. It has also been shown that trade in agricultural products could reduce overall global land and water use. It has been estimated that if countries produced all their own food requirements, global water use would increase about 30\% (Chapagain et al., 2006) and land use would increase about 8\% (Kastner et al., 2014). Thus, international trade in food products need not necessarily be a problem for land and water use.

Even though international trade of land and water use may reduce the global use of water and land, there are still other areas of policy concern (Antonelli and Sartori, 2015). In particular, international trade in land and water use expose the importing countries to concerns about selfsufficiency and food security. Countries become exposed to international food markets and food crises that may be caused by natural disasters, war, climate change, and so on. Further, since the land and water use occurs in distant countries, consumers are no longer (directly) aware of the land and water problems they may be causing, such as, water stress, water pollution, deforestation, land degradation, and so on. Some of these issues may be very location-specific, and temporally specific, making it hard if not impossible to determine a sustainable level of global land and water use. Thus, there are still good reasons to minimise land and water use, to reduce the risks of security issues or causing unintended local environmental problems in distant lands. 
To reduce the land and water footprint, there are several actions that can be taken. A rather obvious strategy is to reduce the consumption of land- and water-intensive products. A typical example would be to consume less meat (Hoekstra and Mekonnen, 2012), although depending on the production system - the intensity of land and water use can vary considerably across different types of land (crop versus pasture) and water (blue, green, grey). On the production side, considerable savings can be captured through yield improvements. In the case of land use, the area under production could be decreased by $35 \%$ through improved yields (Kastner et al., 2014). Blue water use can be reduced through improvements in irrigation technology, similarly for green water systems. Grey water consumption can tend to zero through better management and technology. However, the goal may not be to reduce land and water use to zero, but use land and water within sustainable (local) limits.

\subsection{Material footprints}

\subsubsection{Policy context}

The EU (Eurostat, 2012, European Commission, 2011), the OECD (2011), and UNEP (2011), have been tracking resource efficiency both as a green growth indicator and due to concerns of resource security. The Domestic Material Consumption (DMC) concept has been used for this purpose, primarily taken as a ratio with GDP to measure "productivity" (GDP/DMC) with an increasing productivity implying more GDP for a given material input. The DMC is a measure of "apparent (physical) consumption" and is estimated as the raw materials extracted from the domestic territory plus all physical imports minus all physical exports, and thus only measures physical flows of material in direct trade flows.

The DMC has been criticised because the supply-chain truncation may give a misleading assessment of the actual material requirements. Wiedmann et al. (2015) propose the use of the "material footprint" (sometimes referred to as Raw Material Consumption, RMC) estimated by enumerating all links in the global supply chain, as is typically done with carbon footprints (though not always with land and water footprints). This methodology allocates material extraction to an economic sector, and then a multi-regional inputoutput table is used to link this to final consumption. This leads to two main differences with the DMC. First, all extracted materials, including tailings and waste, are allocated to economic sectors and therefore enter global supply 
chains, whereas in the DMC only materials that are physically transported with trade are included. However, it is possible to change definitions to have consistent system boundaries for the different estimates. Second, just as with other footprints, extracted materials are accumulated along the supply chains even if there is not a physical flow. For example, a telephone would be allocated several tonnes of material consumed or lost along the supply chain, despite the final product weighing less than $100 \mathrm{~g}$.

Material footprints, regardless of method, often aggregate different types of materials together. It is also possible to treat the materials separately, typically as biomass, fossil fuels, construction material, and metal ores. There is value in analysing these flows separately, and this has been done particularly for biomass (Peters et al., 2012), which links to HANPP (Erb et al., 2009), and fossil fuels (Davis et al., 2011), both of which have specific applications and policy implications. However, for policy application, it may be necessary to provide detail down to the level of the material (e.g., lithium), which would require a step-change in the detail of material footprint analysis.

At the global level, (Wiedmann et al., 2015) found that about 70 billion tonnes (Gt) of material (biomass, fossil fuels, construction materials, and metal ores) were extracted and consumed in 2008 , and $41 \%$ of this was either physically or virtually transferred via international trade. This traded volume of $29 \mathrm{Gt}$ was much larger than the 10Gt estimated in direct (physical) trade flows (DMC), highlighting the large difference between the two methodologies. Over time, most countries show a divergence between the material footprints and DMC, most likely because international trade increasingly involves more finished and semi-finished products that are linked to a larger amount of raw materials than is physically contained within them. Due to this divergence, even though many countries and regions (e.g. EU, OECD) have been able to improve resource efficiency via $\mathrm{DMC}$, when using the material footprint the gains in resource efficiency no longer hold, and material consumption grows quite closely with GDP. This growth is largely driven by construction materials.

Figure 13 shows the material footprint of the Nordic countries for biomass, metal ores, construction materials, and fossil fuels using the Eora database (Wiedmann et al., 2015). ${ }^{3}$ The behaviour of the different

\footnotetext{
${ }^{3}$ The figure clearly indicates some data quality issues, including evident problems in Norway's data, with implausible dips in territorial use of metal ores in 2003, and footprints of (at least) metal ores and construction minerals in 1997. In addition, the relative size of Norwegian fossil fuel extraction compared to consumption is much smaller than in fossil-fuel specific studies (Davis et al., 2011). In addition, the territorial data for material flows are only valid until 2008, but the Eora team have chosen to propagate the identical 2008 numbers to later years, and this means that the footprint numbers post-2008 are invalid unless one
} 
material footprints in the Nordic countries varies considerably depending on the material. For biomass, Norway is a net importer, while Sweden and Finland are net exporters. For metal ores, Sweden and Norway are net exporters, while Denmark and Finland are net importers. For construction materials, all the Nordic countries are net importers, with a large increase in the net import over time. For fossil fuels, Sweden and Finland are large net importers and Denmark and especially Norway are large net exporters. Other than for construction materials, where the footprint is growing rapidly, the gap between domestic extraction and the footprint is relatively stable. Since we used pre-calculated results from Eora, we do not have sector or region specific results.

Figure 13: Material footprints for Denmark, Finland, Norway, and Sweden, based on the Eora database (see Footnote 3)
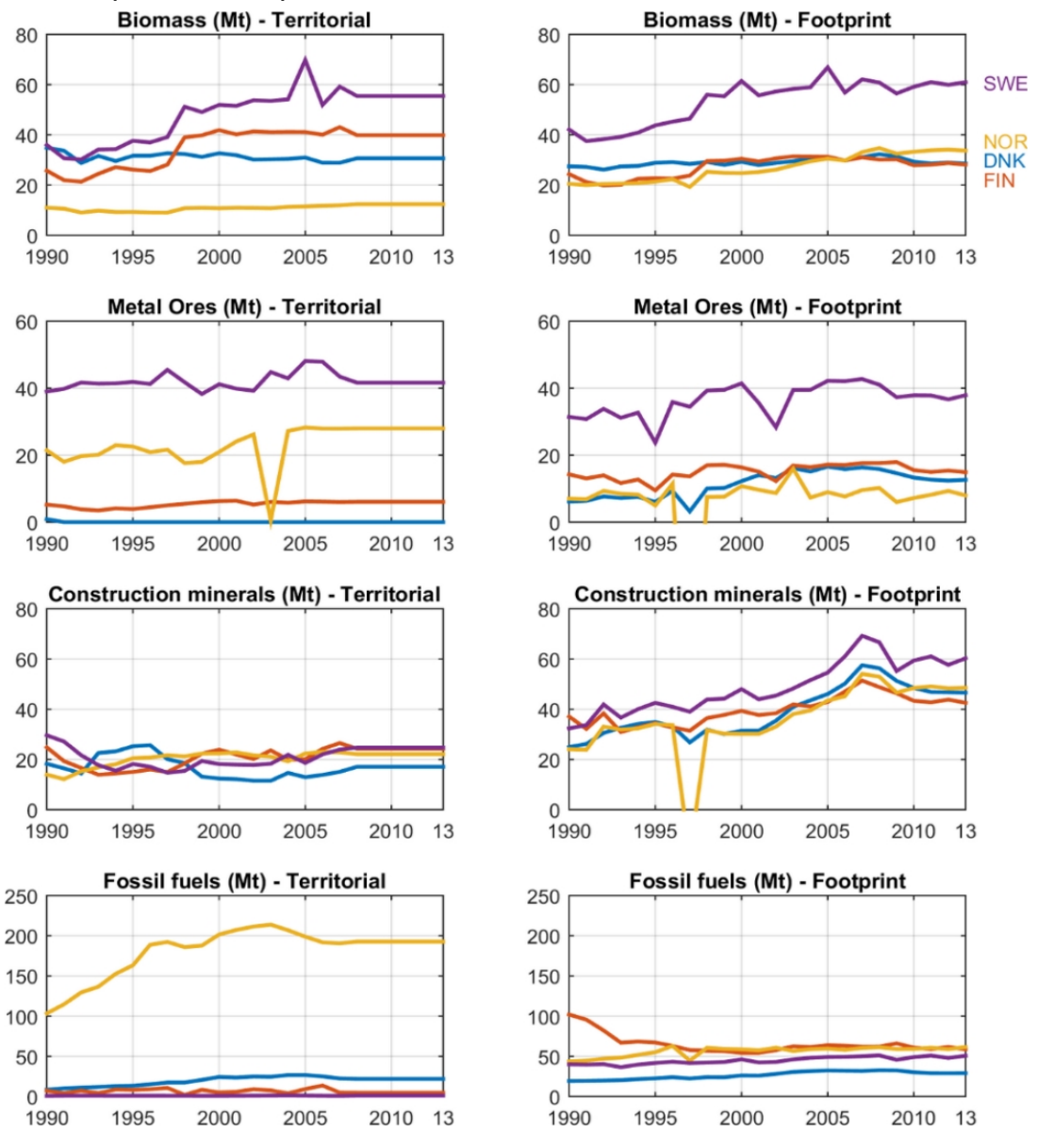

Source: EORA

accepts the assumption that these indicators have not changed since 2008. Such data issues are not documented and would not be apparent if one were to look only at the footprint results. 


\subsubsection{Policies}

Several countries and regions have used resource productivity as an indicator of green growth or a measure of material dependence. Typically, the DMC is used as a productivity measure and shows a relative decoupling of resource use and economic activity, although that trend tends to be broken if the more comprehensive material footprint is used. Very little research has been done on policy instruments that may specifically lead to changes the material footprint.

Many of the issues with policy instruments for land and water footprints also arise with material footprints. It is unclear what the objective of a policy may be, other than to simply reduce the footprint. In contrast to a carbon footprint, there is no specific reason - environmental or otherwise - to reduce material consumption to zero, and it is expected that there will be a certain level of material consumption that is unavoidable. Three key issues are worth noting here. First, the full material footprint includes materials (such as in tailings) that will never physically enter a trade flow. These materials would be classed as a local environmental problem, and there might not be an incentive for a distant country to solve someone else's local environmental problem. Second, if measuring resource efficiency of a domestic economy, the actual efficiency and dependency risks may relate closer to DMC in some cases and the full material footprint in others. Third, the different material types may have quite different policy relevance, and thus it is important to show disaggregated results.

At the policy level, it is difficult to see the usefulness of grouping together these very disparate types of materials beyond simply being able to impress on consumers the enormous mass of material that is required to support the economy and our consumption. Fossil-fuel consumption is much better framed as a resource and energy security issue (Andrew et al., 2013) or a carbon issue (Davis et al., 2011), than as a mass-reliance issue. Similarly, biomass consumption fits more clearly in the policy space of food and fibre security, water and land issues, biodiversity (Lenzen et al., 2012b), and, again, carbon emissions (Peters et al., 2012), and the total amount of biomass is not very relevant for addressing these policy questions. Indeed, with climate policies, it may be expected that fossil fuel consumption tends to zero and biomass consumption increases (Clarke et al., 2014), with an uncertain net impact on the material footprint. Construction materials and metal ore mining may lead to a variety of local pollution problems, but the change in aggregated flows over time could increase or decrease (e.g., increased demand for rare earth materials could increase material flows). There is a long history of estimating the 
total material requirements of the economy, which is the subject of a study by Ayres and Kneese (1969), but the direct policy relevance appears to be limited except for questions of dependence and security.

In terms of specific policies, policies of material use could focus on the consumption or production side. Focusing on the consumption side would amount to changing consumption patterns in a less resourceintensive direction, noting that even some services may indirectly have large material flows (e.g., construction, fossil-fuel consumption for electricity, etc). Focusing on the production side would require more efficient extraction processes (e.g., less waste and tailings) and using less material in all parts of the supply chain. However, it is not clear why a producer would simply reduce the material footprint unless there was an incentive (e.g., environmental degradation, scarcity, cost, and so on). Thus, if some sort of "constraint" was evident, it may be that producers would naturally reduce material consumption to avoid that constraint. It is not clear how a consumer in a distant land would have sufficient information about specific production processes at a product level to enforce a policy upon the producing country.

A noteworthy finding is that improvements in resource efficiency often are driven by decreases in construction materials (Wiedmann et al., 2015). This may indeed represent greater material efficiency, but could also be associated with particular stages in the development cycle. Construction is important in the cycle of development, and in high growth periods may drive carbon emissions (Minx et al., 2011) and other resource consumption in developing countries. Input-output models generally separate capital investments as a final consumption category, because it falls outside of the normal within-year framework of the analytical paradigm, but there are strong arguments to allocate capital investments to the economic sectors indirectly using the capital investments (Lenzen and Treloar, 2004, Peters and Hertwich, 2006). Thus, it is currently hard to assess using input-output analysis what is driving the changes in construction, such as the role of households, governments or export sectors. This is a large gap in the literature, particularly apparent for material footprints but equally relevant to other footprints, and it may be that recent improvements in resource efficiency are simply echoing China's shift away from infrastructure investment towards domestic consumption. 


\section{Using environmental footprints in policy}

An environmental footprint can be estimated for almost any environmental, social, or economic issue, and researchers have tended to do this with the underlying tone that this is a more efficient and fair pathway to sustainability (Hoekstra and Wiedmann, 2014). However, to motivate policy, several conditions need to be met.

First, it is important that there is an objective in reducing the footprint. In the case of greenhouse gas emissions, the Paris Agreement has specified that global average temperatures should be kept well below $2^{\circ} \mathrm{C}$ above preindustrial levels, and greenhouse gas emissions should become net zero in the period 2050-2100 (UNFCCC, 2015). Given these limits, and the fragmented implementation of climate policies, there is a clear narrative for why one would consider a carbon footprint in policy. For most other environmental footprints, it is not clear where sustainable limits may lie (Hoekstra and Wiedmann, 2014) and, ultimately, the limits might be at a local level. There is unlikely to be a global policy addressing water, land, or material use. If the goal of the policy is clearly stated, then it is possible to debate whether conventional territorial policies are most suitable, or if footprint-based policies could have advantages.

Second, the largest share of an environmental footprint generally occurs domestically, with a much smaller amount related to imported flows. Given that there will be at least transaction costs in a shift to a footprint approach, even as a complementary indicator, it is important to investigate policies that predominantly affect the import component of the footprint. We suggest a careful delineation between policies addressed at consumers and policies that address the import-related part of the footprint.

Third, environmental footprints need to be sufficiently accurate and tractable to reliably implement the policy and assess progress after policy implementation. If not sufficiently accurate and tractable within the limits of the methodology, a variety of (footprint) policy options may not be worth considering until methods improve.

Despite the intellectual appeal of environmental footprints, careful thought has to be put into mapping a pathway from monitoring (today"s 
situation) to policy implementation (a potential future pathway). Here, we briefly summarise key findings from Chapters 2 and 3 to discuss whether there is a policy implementation pathway, and for what environmental footprints. We do not discuss individual policies, but discuss the conceptual background that needs to be considered to arrive at potential policies. We first focus on uncertainty and reliability, and then policy aspects.

\subsection{Uncertainty and reliability}

Current environmental footprints are suitable for tracking progress, understanding more holistically the drivers of environmental problems, scoping potential areas of policy analysis, and framing discussions of the international dimensions of consumption and policy coherence. These aspects are important and worth pursuing. But, estimates of environmental footprints are probably insufficient to adequately support the implementation of concrete policies, despite considerable progress in recent years. There are several reasons we take this view of the quality of environmental footprints:

Consistency. There are now several global MRIO datasets that can be used for environmental footprint estimates. To construct these tables requires balancing conflicting data, which necessitates modifying potentially millions of officially reported data points. Although it is possible to assign reliability automatically to different data points (Lenzen et al., 2012a), it is not possible to validate whether the changes are an improvement over the officially reported data. A MRIO table may be technically inconsistent with the national accounts in every country. While this may lead to better global datasets, it is perhaps a situation most countries would rather avoid since inconsistencies with national accounting data appear (Edens et al., 2015).

Quality. Comparisons of independent MRIO tables tend to report that they are broadly "consistent" (Moran and Wood, 2014, Peters et al., 2012). Consistency requires careful definition, as consistency of MRIO tables in the literature is generally not quantified and, if it is, it is generally applied to large countries that naturally have less uncertainty. As shown in Chapter 2, for smaller individual countries, environmental footprints are broadly consistent for $\mathrm{CO}_{2}$, but this implies they have qualitatively the same magnitude and trend. Uncertainties in environmental footprints can be counterintuitively less than territorial estimates, which may just reflect methodological obscurities rather than analytical robustness. For 
other environmental footprints (water, land, materials) there are scant data available for cross-country comparisons. Further, even a layperson can spot potential problems with "off-the-shelf" estimates of environmental footprints from global datasets, which undermines confidence in the quality of the remaining data.

Aggregation. Global environmental footprint estimates are usually at a high level of sector aggregation, usually $25-100$ sectors in each country. This may be adequate to track progress in the total footprint, but at the sector level, uncertainties can be prohibitively high (Karstensen et al., 2015b). The implementation of policy would generally require significantly more detail, which is not feasible for most MRIO tables. To implement a policy aimed at the carbon footprint, estimates might be needed at the level of an individual facility and product, as they could have substantially different values. To implement a policy to address land and water footprints may require detail at the level of a river basin, to determine whether land or water is used sustainability in that basin, regardless of the national trend.

Targeting. Policy would necessarily need to target specific problems in the supply chain. An aggregated footprint, such as metal ores, may not allow targeting particular issues in the mining sector, which may relate to particular contaminants of small volume. A footprint may indicate the volume of material extracted, but policy may require much more specific information on the type of materials and environmental or resource problem. As for all footprints, these environmental issues may vary from facility to facility, making it very difficult to implement specific policies.

Interpretation. One can argue that for many of the reasons outlined above, there is likely to be uncertainty in the interpretation of environmental footprint results. A growing footprint may indicate a problem that needs to be addressed, but deeper analysis may reveal that the change is consistent with policy and to be expected. Environmental footprints are the aggregation of a variety of concepts (e.g., definition of consumptive water use), aggregation, and estimation errors, and these can all skew interpretation.

Even though researchers have begun to investigate some of these uncertainties and quality issues, we believe much more research is required to adequately characterise the various estimation issues of environmental footprints. The differences between structural and parametric uncertainties are not fully appreciated. The uncertainty in environmental and economic accounts needs further elaboration, and we believe that greater emphasis is required on resolving persistent uncertainties in the environmental accounts. 


\subsection{Policy applicability}

The desire to reduce the size of national-level environmental footprints should be seen in light of a given environmental objective. That objective may be linked to a given environmental goal, target or boundary, it could be framed in the context of security of supply and independence. It is possible that the policy significance will change depending on whether the resource is renewable or non-renewable, on whether the problem is global or local, and on the level of aggregation (across and within different footprints).

Climate: For climate, greenhouse gas emissions must go to zero around 2050-2100 (Clarke et al., 2014). Further, greenhouse gas emissions are global pollutants, and the climate impact is virtually independent of the location of the emissions. Thus, a global policy response is needed. Since climate policies have been implemented in a fragmented way, some countries with policies and some without, the need for consumption-based indicators (carbon footprints) is clear. There is also a clear set of policy responses. One could argue that the case has been made for consumption-based approaches in climate policy, and that it is just a question of whether the gains of shifting to a (complementary) consumption-based system offset the losses. Our assessment of the literature, however, is that the case for consumption-based policies has yet to be made.

Other footprints: For most other environmental problems, it is not clear that the goal, boundary or target will be zero, implying that there is some sustainable level of consumption (Hoekstra and Wiedmann, 2014). In many cases, that sustainable level may show extreme variations between local regions. Water may be abundant in some regions, but scarce in others, and it has been suggested this should be assessed at the basin level (Hoekstra et al., 2011). In this case, the global "boundary" needs to be translated to a local level incorporating local characteristics. The relevance of a nationallevel environmental footprint starts to dissipate, as one needs to assess the flows of individual products coming from individual basins (in the case of water). This problem can partially be resolved by linking, at the local scale, the footprint with some measure of scarcity as has been done for water (Feng et al., 2014). But, ultimately, if a more local and direct environmental problem is identified, a conventional territorial- or production-based approach may be more appropriate.

Aggregation: When defining environmental goals, targets, or boundaries, the level of disaggregation becomes important. A material footprint often aggregates fossil fuels, biomass, construction materials 
and metals. However, fossil fuels are potentially best dealt with via a carbon footprint, and biomass may link more closely to carbon, land, and/or water footprints. It is perhaps useful to know how much material is used by society, but disaggregation is necessary for policy implementation. A similar issue arises with water and the need to separate green, blue, and grey water for policy purposes, and perhaps even refine definitions to more closely map to policy needs. As a minimum, the analyst should clearly explain definitions and assumptions when presenting environmental footprints, and give the option to have the data at the most detailed level suitable for the policy application.

Definitions: Particular policy applications may warrant specific definitions. A material footprint, even if just for metal ores, could include mine tailings, but this may not be particularly relevant for the policy (e.g., if resource security of a raw earth metal). Further, in a top-down economic supply chain analysis, the footprint can be large in unexpected sectors, such as land use in the health sector (via food consumption) or fossil fuel use in the retail sector (via electricity consumption). Thus, it is worthwhile to highlight the differences between physical and nonphysical ("virtual") flows, and particularly to discuss or quantify how much non-physical flow is included in different environmental footprints, and to discuss the relevance for policy.

Security and dependence: Policies associated with security of supply or independence, or indeed resource efficiency, may require modified versions of environmental footprints that only capture the relevant flows. Measuring the mass of mine tailings may not be relevant for security of supply or resource efficiency. Likewise, water flows may only be relevant when weighted with a measure of scarcity. This does not argue against using footprint indicators, but rather emphasises that the indicators need to be tailored to the exact application.

\subsection{Future perspectives}

Given the current level of country-level uncertainty, and that uncertainty increases with levels of disaggregation relevant for policy, we suggest continued monitoring, reporting, and verification of environmental footprints across a range of relevant categories (carbon, energy, land, water, materials) and their respective sub-categories. It is perhaps too premature to implement policies with the aim of quantifiably reducing the imported part of an environmental footprint. 
Tracking: There are several advantages of tracking environmental footprints. First, consumers (household, government, industry) can be made aware of the global dimensions of their consumption decisions, and this may act - on the margin - to reduce environmental footprints. Second, the methodologies used to construct environmental footprints allow a detailed tracking of consumption to production and environmental impacts, and detailed analysis of the resulting datasets may reveal relevant areas for policy implementation. Third, tracking regularly over time allows rapid changes to be identified, and potentially measures to be taken to either enhance a positive gain or to reverse a negative trend. Fourth, a strong monitoring, reporting, and - importantly - verification process will ensure methods are improved in a direction most relevant for policy. Finally, tracking will give an important baseline for future policy implementation.

Methodologies: We believe that despite the positive progress in methodologies in recent years through the development of multiple independent multi-region input-output tables, there are still significant improvements to be made. The sheer size, complexity, and automation of some new datasets may be technically impressive feats, but the level of uncertainty is still too high for many policy applications. Resources should be focussed on understanding the trade-offs between different methods of data reconciliation, and independently driving down uncertainty. Much more diversity is needed in estimates of water and land accounts. And there needs to be much greater understanding of methodological choices, definitions, and assumptions used in environmental accounts. With these improvements underway, greater clarity will be obtained on policy options.

Policy: From the policy perspective, a much clearer motivation for using environmental footprints is required. At the moment, it seems that environmental footprints are estimated and advocates then try to push environmental footprints onto policy makers. There needs to be a greater push from policy makers on what is the problem to be solved, with researchers then potentially disaggregating estimates or refining definitions, to match policy goals more closely. This will ultimately be a partnership between policy makers and researchers, as there may be limits to what footprints can estimate with sufficient accuracy required to effectively implement policies. 


\section{References}

AHMAD, N. \& WYCKOFF, A. 2003. Carbon dioxide emissions embodied in international trade of goods. Organisation for Economic Co-operation and Development (OECD).

ALLEN, J. A. 1992. Fortunately there are substitutes for water otherwise our hydropolitical futures would be impossible. Priorities for water resources allocation and management. Southampton, UK: Overseas Development Administration.

ANDREW, R. \& FORGIE, V. 2011. An Analysis of New Zealand's Ecological Footprint as Estimated by the Global Footprint Network: An Update. Palmerston North, NZ: Landcare Research and Ecological Economics Research NZ.

ANDREW, R. M., DAVIS, S. J. \& PETERS, G. P. 2013. Climate policy and dependence on traded carbon. Environmental Research Letters, 8, 034011.

ANTONELLI, M. \& SARTORI, M. 2015. Unfolding the potential of the virtual water concept. What is still under debate? Environmental Science \& Policy, 50, 240-251.

AYRES, R. U. \& KNEESE, A. V. 1969. Production, Consumption, and Externalities. The American Economic Review, 59, 282-297.

BARRETT, J., PETERS, G., WIEDMANN, T., SCOTT, K., LENZEN, M., ROELICH, K. \& LE QUÉRÉ, C. 2013. Consumption-based GHG emission accounting: a UK case study. Climate Policy, 13, 451-470.

BEATTIE, G. 2012. Psychological effectiveness of carbon labelling. Nature Clim. Change, 2, 214-217.

BEDNAR-FRIEDL, B., SCHINKO, T. \& STEININGER, K. W. 2012. The relevance of process emissions for carbon leakage: A comparison of unilateral climate policy options with and without border carbon adjustment. Energy Economics, 34, S168-S180.

BÖHRINGER, C., BALISTRERI, E. J. \& RUTHERFORD, T. F. 2012a. The role of border carbon adjustment in unilateral climate policy: Overview of an Energy Modeling Forum study (EMF 29). Energy Economics, 34, Supplement 2, S97-S110.

BÖHRINGER, C., CARBONE, J. \& RUTHERFORD, T. 2012b. Unilateral climate policy design: efficiency and equity implications of alternative instruments to reduce carbon leakage. Energy Economics.

BORGSTRÖM, G. 1965. The Hungry Planet: the modern world at the edge of famine, New York, Macmillan.

CHAPAGAIN, A. K., HOEKSTRA, A. Y. \& SAVENIJE, H. H. G. 2006. Water saving through international trade of agricultural products. Hydrology and Earth System Sciences, $10,455-468$. 
CLARKE, L., JIANG, K., AKIMOTO, K., BABIKER, M., BLANFORD, G., FISHER-VANDEN, K., HOURCADE, J.-C., KREY, V., KRIEGLER, E., LÖSCHEL, A., MCCOLLUM, D., PALTSEV, S., ROSE, S., SHUKLA, P. R., TAVONI, M., ZWAAN, B. V. D. \& VUUREN, D. P. V. 2014. Assessing Transformation Pathways. In: EDENHOFER, O., PICHSMADRUGA, R., SOKONA, Y., FARAHANI, E., KADNER, S., SEYBOTH, K., ADLER, A., BAUM, I., BRUNNER, S., EICKEMEIER, P., KRIEMANN, B., SAVOLAINEN, J., SCHLÖMER, S., STECHOW, C. V., ZWICKEL, T. \& MINX, J. C. (eds.) Climate Change 2014: Mitigation of Climate Change. Contribution of Working Group III to the Fifth Assessment Report of the Intergovernmental Panel on Climate Change. Cambridge University Press, Cambridge, United Kingdom and New York, NY, USA.

COSBEY, A., DROEGE, S., FISCHER, C., REINAUD, J., STEPHENSON, J., WEISCHER, L. \& WOODERS, P. 2012. A Guide for the Concerned: Guidance on the elaboration and implementation of border carbon adjustment. ENTWINED Policy Report 3.

CUYPERS, D., PETERS, G. P., PRIELER, S., GEERKEN, T., KARSTENSEN, J., FISHER, G., GORISSEN, L., HIZSNYIK, E., LUST, A. \& VELTHUIZEN, H. V. 2013. The impact of EU consumption on deforestation: Comprehensive analysis of the impact of EU consumption on deforestation.

DAUDIN, G., MONPERRUS-VERONI, P., RIFFLART, C. \& SCHWEISGUTH, D. 2006. Le Commerce Extérieur En Valeur Ajoutée. Revue de "OFCE, 98, 129-165.

DAVIS, S. J. \& CALDEIRA, K. 2010. Consumption-based accounting of $\mathrm{CO}_{2}$ emissions. Proceeding of the National Academy of Sciences, 107, 5687-5692.

DAVIS, S. J., PETERS, G. P. \& CALDEIRA, K. 2011. The supply chain of $\mathrm{CO}_{2}$ emissions. Proceedings of the National Academy of Sciences, 108, 18554-18559.

DIETZ, T., GARDNER, G. T., GILLIGAN, J., STERN, P. C. \& VANDENBERGH, M. P. 2009. Household actions can provide a behavioral wedge to rapidly reduce US carbon emissions. Proceedings of the National Academy of Sciences, 106, 18452-18456.

EDENS, B., HOEKSTRA, R., ZULT, D., LEMMERS, O., WILTING, H. \& WU, R. 2015. A METHOD TO CREATE CARBON FOOTPRINT ESTIMATES CONSISTENT WITH NATIONAL ACCOUNTS. Economic Systems Research, 27, 440-457.

ERB, K.-H., KRAUSMANN, F., LUCHT, W. \& HABERL, H. 2009. Embodied HANPP: Mapping the spatial disconnect between global biomass production and consumption. Ecological Economics, 63, 328-334.

ERCIN, A. E. \& HOEKSTRA, A. Y. 2012. Carbon and Water Footprints: Concepts, Methodologies and Policy Responses. Paris: UNESCO.

EUROPEAN COMMISSION 2001. Nameas for air emissions: Results of pilot studies, Luxembourg, European Communities.

EUROPEAN COMMISSION 2009. Emission Database for Global Atmospheric Research (EDGAR), release version 4.0. Joint Research Centre (JRC) and Netherlands Environmental Assessment Agency (PBL).

EUROPEAN COMMISSION 2011. Roadmap to a Resource Efficient Europe. COM(2011)571 Final, Brussels, European Commission.

EUROSTAT 2012. Sustainable Development Indicators, Luxembourg, Statistical Office of the European Communities.

FELDER, S. \& RUTHERFORD, T. F. 1993. Unilateral $\mathrm{CO}_{2}$ Reductions and Carbon Leakage: The Consequences of International Trade in Oil and Basic Materials. Journal of Environmental Economics and Management, 25, 162-176.

FENG, K., HUBACEK, K., PFISTER, S., YU, Y. \& SUN, L. 2014. Virtual Scarce Water in China. Environmental Science \& Technology, 48, 7704-7713. 
FISCHER, C. \& FOX, A. K. 2012. Comparing policies to combat emissions leakage: Border carbon adjustments versus rebates. Journal of Environmental Economics and Management, 64, 199-216.

GILJUM, S., LUTTER, S., BRUCKNER, M. \& APARCANA, S. 2013. State-of-play of National Consumption-Based Indicators: A review and evaluation of available methods and data to calculate footprint-type (consumption-based) indicators for materials, water, land and carbon. Sustainable Europe Research Institute (SERI).

GILJUM, S., LUTTER, S., WIELAND, H., EISENMENGER, N., WIEDENHOFER, D., SCHAFFARTZIK, A., SCHANDL, H. \& WEST, J. 2015. An Empirical Assessment Comparing Input-Output-Based and Hybrid Methodologies to Measure DemandBased Material Flows. Paris: OECD.

GILLINGHAM, K., KOTCHEN, M. J., RAPSON, D. S. \& WAGNER, G. 2013. Energy policy: The rebound effect is overplayed. Nature, 493, 475-476.

HABERL, H., ERB, K.-H. \& KRAUSMANN, F. 2010. Global human appropriation of net primary production (HANPP) [Online]. Available: http://www.eoearth.org/article/ Global_human_appropriation_of_net_primary_production_(HANPP) [Accessed March 2011].

HABERL, H., ERB, K. H., KRAUSMANN, F., GAUBE, V., BONDEAU, A., PLUTZAR, C., GINGRICH, S., LUCHT, W. \& FISCHER-KOWALSKI, M. 2007. Quantifying and mapping the human appropriation of net primary production in earth's terrestrial ecosystems. Proceedings of the National Academy of Sciences of the USA, 104, 12942-12947.

HERTWICH, E. G. 2005. Consumption and the Rebound Effect: An Industrial Ecology Perspective. Journal of Industrial Ecology, 9, 85-98.

HERTWICH, E. G. 2011. The life cycle environmental impacts of consumption. Economic Systems Research, 23, 27-47.

HERTWICH, E. G. \& PETERS, G. P. 2009. Carbon Footprint of Nations: A Global, TradeLinked Analysis. Environmental Science and Technology, 43, 6414-6420.

HOEKSTRA, A. Y., CHAPAGAIN, A. K., ALDAYA, M. M. \& MEKONNE, M. M. 2011. The Water Footprint Assessment Manual: Setting the Global Standard, London, Washington, D.C., Earthscan.

HOEKSTRA, A. Y. \& MEKONNEN, M. M. 2012. The water footprint of humanity. Proceedings of the National Academy of Sciences.

HOEKSTRA, A. Y. \& WIEDMANN, T. O. 2014. Humanity's unsustainable environmental footprint. Science, 344, 1114-1117.

HOEL, M. 1996. Should a carbon tax be differentiated across sectors? Journal of Public Economics, 59, 17-32.

HORN, H. \& MAVROIDIS, C. 2010. Climate Change and the WTO: Legal Issues Concerning Border Tax Adjustments. Japanese Yearbook of International Law, 53, 19-40.

INOMATA, S. \& OWEN, A. 2014. COMPARATIVE EVALUATION OF MRIO DATABASES. Economic Systems Research, 26, 239-244.

JAKOB, M., MARSCHINSKI, R. \& HÜBLER, M. 2013. Between a Rock and a Hard Place: A Trade-Theory Analysis of Leakage Under Production- and Consumption-Based Policies. Environmental and Resource Economics, 56, 47-72.

KANEMOTO, K., MORAN, D., LENZEN, M. \& GESCHKE, A. 2014. International trade undermines national emission reduction targets: New evidence from air pollution. Global Environmental Change, 24, 52-59.

KARSTENSEN, J., PETERS, G. \& ANDREW, R. 2015a. Allocation of global temperature change to consumers. Climatic Change, 129, 43-55. 
KARSTENSEN, J., PETERS, G. P. \& ANDREW, R. M. 2015b. Uncertainty in temperature response of current consumption-based emissions estimates. Earth Syst. Dynam., 6, 287-309.

KASTNER, T., ERB, K.-H. \& HABERL, H. 2014. Rapid growth in agricultural trade: effects on global area efficiency and the role of management. Environmental Research Letters, 9, 034015.

KOLSTAD, C., URAMA, K., BROOME, J., BRUVOLL, A., OLVERA, M. C., FULLERTON, D., GOLLIER, C., HANEMANN, W. M., HASSAN, R., JOTZO, F., KHAN, M. R., MEYER, L. \& MUNDACA, L. 2014. Social, Economic and Ethical Concepts and Methods. In: EDENHOFER, O., PICHS-MADRUGA, R., SOKONA, Y., FARAHANI, E., KADNER, S., SEYBOTH, K., ADLER, A., BAUM, I., BRUNNER, S., EICKEMEIER, P., KRIEMANN, B., SAVOLAINEN, J., SCHLÖMER, S., STECHOW, C. V., ZWICKEL, T. \& MINX, J. C. (eds.) Climate Change 2014: Mitigation of Climate Change. Contribution of Working Group III to the Fifth Assessment Report of the Intergovernmental Panel on Climate Change. Cambridge University Press, Cambridge, United Kingdom and New York, NY, USA.

KOOPMAN, R., WANG, Z. \& WEI, S.-J. 2014. Tracing Value-Added and Double Counting in Gross Exports. American Economic Review, 104, 459-494.

LE QUÉRÉ, C., MORIARTY, R., ANDREW, R. M., CANADELL, J. G., SITCH, S., KORSBAKKEN, J. I., FRIEDLINGSTEIN, P., PETERS, G. P., ANDRES, R. J., BODEN, T. A., HOUGHTON, R. A., HOUSE, J. I., KEELING, R. F., TANS, P., ARNETH, A., BAKKER, D. C. E., BARBERO, L., BOPP, L., CHANG, J., CHEVALLIER, F., CHINI, L. P., CIAIS, P., FADER, M., FEELY, R. A., GKRITZALIS, T., HARRIS, I., HAUCK, J., ILYINA, T., JAIN, A. K., KATO, E., KITIDIS, V., KLEIN GOLDEWIJK, K., KOVEN, C., LANDSCHÜTZER, P., LAUVSET, S. K., LEFÈVRE, N., LENTON, A., LIMA, I. D., METZL, N., MILLERO, F., MUNRO, D. R., MURATA, A., NABEL, J. E. M. S., NAKAOKA, S., NOJIRI, Y., O’BRIEN, K., OLSEN, A., ONO, T., PÉREZ, F. F., PFEIL, B., PIERROT, D., POULTER, B., REHDER, G., RÖDENBECK, C., SAITO, S., SCHUSTER, U., SCHWINGER, J., SÉFÉRIAN, R., STEINHOFF, T., STOCKER, B. D., SUTTON, A. J., TAKAHASHI, T., TILBROOK, B., VAN DER LAAN-LUIJKX, I. T., VAN DER WERF, G. R., VAN HEUVEN, S., VANDEMARK, D., VIOVY, N., WILTSHIRE, A., ZAEHLE, S. \& ZENG, N. 2015. Global Carbon Budget 2015. Earth Syst. Sci. Data, 7, 349-396.

LENZEN, M. 2000a. Errors in Conventional and Input-Output-based Life-Cycle Inventories. Journal of Industrial Ecology, 4, 127-148.

LENZEN, M. Uncertainty in IO-based LCI. In: NIELSEN, A. M. \& WEIDEMA, B. P., eds. Input/Output analysis - Shortcuts to life cycle data?, 29 September $20002000 \mathrm{~b}$ Copenhagen. Danish Environmental Protection Agency, 17-27.

LENZEN, M., KANEMOTO, K., MORAN, D. \& GESCHKE, A. 2012a. Mapping the Structure of the World Economy. Environmental Science \& Technology, 46, 8374-8381.

LENZEN, M., MORAN, D., BHADURI, A., KANEMOTO, K., BEKCHANOV, M., GESCHKE, A. \& FORAN, B. 2013. International trade of scarce water. Ecological Economics, 94, 78-85.

LENZEN, M., MORAN, D., KANEMOTO, K., FORAN, B., LOBEFARO, L. \& GESCHKE, A. 2012b. International trade drives biodiversity threats in developing nations. Nature, 486, 109-112.

LENZEN, M. \& TRELOAR, G. 2004. Endogenising capital - a comparison of two methods. Journal of Applied Input-Output Analysis, 10, 1-11.

LENZEN, M., WOOD, R. \& WIEDMANN, T. 2010. UNCERTAINTY ANALYSIS FOR MULTI-REGION INPUT-OUTPUT MODELS - A CASE STUDY OF THE UK'S CARBON FOOTPRINT. Economic Systems Research, 22, 43-63.

LEONTIEF, W. 1970. Environmental repercussions and the economic structure: An input-output approach. The Review of Economics and Statistics, 52, 262-271. 
LIPSEY, R. G. \& LANCASTER, K. 1956. The General Theory of Second Best. The Review of Economic Studies, 24, 11-32.

LOS, B., TIMMER, M. P. \& DE VRIES, G. J. 2015. HOW GLOBAL ARE GLOBAL VALUE CHAINS? A NEW APPROACH TO MEASURE INTERNATIONAL FRAGMENTATION. Journal of Regional Science, 55, 66-92.

MACKNICK, J. 2011. Energy and $\mathrm{CO}_{2}$ emission data uncertainties. Carbon Management, 2, 189-205.

MARKUSEN, J. R. 1975. International externalities and optimal tax structures. Journal of International Economics, 5, 15-29.

MARLAND, G., HAMAL, K. \& JONAS, M. 2009. How Uncertain Are Estimates of $\mathrm{CO}_{2}$ Emissions? Journal of Industrial Ecology, 13, 4-7.

MENG, B., ZHANG, Y. \& INOMATA, S. 2012. Compilation, Application and Challenge of IDE-JETRO's International Input-Output Tables. Institute of Developing Economies.

MINX, J. C., BAIOCCHI, G., PETERS, G. P., WEBER, C. L., GUAN, D. \& HUBACEK, K. 2011. A “Carbonizing Dragon": China's Fast Growing $\mathrm{CO}_{2}$ Emissions Revisited. Environmental Science \& Technology, 45, 9144-9153.

MORAN, D. \& WOOD, R. 2014. CONVERGENCE BETWEEN THE EORA, WIOD, EXIOBASE, AND OPENEU'S CONSUMPTION-BASED CARBON ACCOUNTS. Economic Systems Research, 26, 245-261.

MUNKSGAARD, J. \& PEDERSEN, K. A. 2001. $\mathrm{CO}_{2}$ accounts for open economies: Producer or consumer responsibility? Energy Policy, 29, 327-334.

MYHRE, G., SHINDELL, D., BRÉON, F.-M., COLLINS, W., FUGLESTVEDT, J., HUANG, J., KOCH, D., LAMARQUE, J.-F., LEE, D., MENDOZA, B., NAKAJIMA, T., ROBOCK, A., STEPHENS, G., TAKEMURA, T. \& ZHANG, H. 2013. Anthropogenic and Natural Radiative Forcing. In: STOCKER, T. F., QIN, D., PLATTNER, G.-K., TIGNOR, M., ALLEN, S. K., BOSCHUNG, J., NAUELS, A., XIA, Y., BEX, V. \& MIDGLEY, P. M. (eds.) Climate Change 2013: The Physical Science Basis. Contribution of Working Group I to the Fifth Assessment Report of the Intergovernmental Panel on Climate Change. Cambridge, United Kingdom and New York, NY, USA: Cambridge University Press.

OECD 2011. Towards Green Growth: Monitoring Progress (OECD Indicators), Paris, Organisation for Economic Co-operation and Development.

OECD. 2015. Measuring Trade in Value Added: An OECD-WTO joint initiative [Online]. Available: http://www.oecd.org/sti/ind/measuringtradeinvalue-addedanoecdwtojointinitiative.htm [Accessed 29 March 2016].

PAUWLYN, J. 2012. Carbon Leakage Measures and Border Tax Adjustments under WTO Law. In: PREVOST, D. \& CALSTER, G. V. (eds.) Research Handbook on Environment, Health and the WTO. Cheltenham, UK: Edward Elgar.

PEDERSEN, O. G. \& DE HAAN, M. 2006. The System of Environmental and Economic Accounts-2003 and the Economic Relevance of Physical Flow Accounting. Journal of Industrial Ecology, 10, 19-42.

PETERS, G. \& SOLLI, C. 2010. Global carbon footprints: Methods and import/export corrected results from the Nordic countries in global carbon footprint studies.

PETERS, G. P. 2007. Efficient Algorithms for Life Cycle Assessment, Input-Output Analysis, and Monte-Carlo Analysis. International Journal of Life Cycle Assessment, 12, 373-380.

PETERS, G. P. 2008. From Production-Based to Consumption-Based National Emission Inventories. Ecological Economics, 65, 13-23.

PETERS, G. P. 2010a. Carbon footprints and embodied carbon at multiple scales. Current Opinion on Environmental Sustainability, 2, 245-250.

PETERS, G. P. 2010b. Managing Carbon Leakage. Carbon Management, 1, 35-37. 
PETERS, G. P. \& ANDREW, R. 2012. A multi-region input-output table based on the global trade analysis project database. Frontier of International Input-Output Analyses. Tokyo, Japan.

PETERS, G. P., ANDREW, R. \& LENNOX, J. 2011a. Constructing a multi-regional inputoutput table using the GTAP database. Economic Systems Research, 23, 131-152.

PETERS, G. P., DAVIS, S. J. \& ANDREW, R. 2012. A synthesis of carbon in international trade. Biogeosciences, 9, 3247-3276.

PETERS, G. P. \& HERTWICH, E. G. 2006. Pollution embodied in trade: The Norwegian case. Global Environmental Change, 16, 379-389.

PETERS, G. P. \& HERTWICH, E. G. 2008a. $\mathrm{CO}_{2}$ Embodied in International Trade with Implications for Global Climate Policy. Environmental Science and Technology, 42, 1401-1407.

PETERS, G. P. \& HERTWICH, E. G. 2008b. Post-Kyoto Greenhouse Gas Inventories: Production versus Consumption. Climatic Change, 86, 51-66.

PETERS, G. P., MARLAND, G., HERTWICH, E. G., SAIKKU, L., RAUTIAINEN, A. \& KAUPPI, P. E. 2009. Trade, Transport, and Sinks Extend the Carbon Dioxide Responsibility of Countries. Climatic Change, 97, 379-388.

PETERS, G. P., MINX, J. C., WEBER, C. L. \& EDENHOFER, O. 2011b. Growth in emission transfers via international trade from 1990 to 2008. Proceedings of the National Academy of Sciences, 108, 8903-8908.

REES, W. 1992. Ecological footprints and appropriated carrying capacity: What urban economics leaves out. Environment and Urbanization, 4, 121-130.

REINVANG, R. \& PETERS, G. P. 2008. Norwegian Consumption, Chinese Pollution. World Wildlife Fund Norway, World Wildlife Fund China and the Industrial Ecology Programme at the Norwegian University of Science and Technology.

SAISANA, M. \& TARANTOLA, S. 2002. State-of-the-art Report on Current Methodologies and Practices for Composite Indicator Development. Ispra, Italy: European Commission Joint Research Centre.

SATO, K. \& SHRESTHA, N. 2014. Global and Regional Shock Transmission: An Asian Perspective. Research Center for Economic and Social Statistics in Asia, Yokohama National University.

SMIL, V. 2008. Water News: Bad, Good and Virtual. American Scientist, 96, 399.

SMIL, V. 2013. Harvesting the Biosphere: What we have taken from Nature, Cambridge, Massachusetts; London, England, The MIT Press.

SPRINGMANN, M. 2014. Integrating emissions transfers into policy-making. Nature Clim. Change, 4, 177-181.

STEEN-OLSEN, K., WEINZETTEL, J., CRANSTON, G., ERCIN, A. E. \& HERTWICH, E. G. 2012. Carbon, Land, and Water Footprint Accounts for the European Union: Consumption, Production, and Displacements through International Trade. Environmental Science \& Technology, 46, 10883-10891.

STEG, L. \& VLEK, C. 2009. Encouraging pro-environmental behaviour: An integrative review and research agenda. Journal of Environmental Psychology, 29, 309-317.

STEININGER, K., LININGER, C., DROEGE, S., ROSER, D., TOMLINSON, L. \& MEYER, L. 2014. Justice and cost effectiveness of consumption-based versus production-based approaches in the case of unilateral climate policies. Global Environmental Change, 24, 75-87.

STERN, P. 1999. Information, Incentives, and Proenvironmental Consumer Behavior. Journal of Consumer Policy, 22, 461-478. 
TIMMER, M. P., DIETZENBACHER, E., LOS, B., STEHRER, R. \& DE VRIES, G. J. 2015. An Illustrated User Guide to the World Input-Output Database: the Case of Global Automotive Production. Review of International Economics, 23, 575-605.

TIMMER, M. P., ERUMBAN, A. A., LOS, B., STEHRER, R. \& DE VRIES, G. J. 2014. Slicing Up Global Value Chains. Journal of Economic Perspectives, 28, 99-118.

TSIGAS, M., WANG, Z. \& GEHLHAR, M. 2012. How a Global Inter-Country InputOutput Table with Processing Trade Account can be constructed from GTAP Database. 15th GTAP Conference on Global Economic Analysis. Geneva.

TUKKER, A., COHEN, M. J., HUBACEK, K. \& MONT, O. 2010. The Impacts of Household Consumption and Options for Change. Journal of Industrial Ecology, 14, 13-30.

TUKKER, A. \& DIETZENBACHER, E. 2013. GLOBAL MULTIREGIONAL INPUTOUTPUT FRAMEWORKS: AN INTRODUCTION AND OUTLOOK. Economic Systems Research, 25, 1-19.

UN 2014. System of Environmental-Economic Accounting 2012: Central Framework, New York, United Nations, European Union, Food and Agriculture Organization of the United Nations, International Monetary Fund, Organisation for Economic Cooperation and Development, The World Bank.

UNEP 2011. Decoupling Natural Resource Use and Environmental Impacts from Economic Growth, Nairobi, United Nations Environment Programme.

UNEP 2012. The Emissions Gap Report 2012 - Appendix 1. Nairobi.

UNFCCC 2015. Adoption of the Paris Agreement. United Nations Framework Convention on Climate Chance, FCCC/CP/2015/L.9/Rev.1.

UNITED NATIONS, COMMISSION OF THE EUROPEAN COMMUNITIES - EUROSTAT, INTERNATIONAL MONETARY FUND, ORGANISATION FOR ECONOMIC COOPERATION AND DEVELOPMENT \& WORLD BANK 1993. System of National Accounts 1993, Brussels/Luxembourg, New York, Paris, Washington, D.C.

VAN DEN BERGH, J. C. J. M. \& GRAZI, F. 2014. Ecological Footprint Policy? Land Use as an Environmental Indicator. Journal of Industrial Ecology, 18, 10-19.

VAN DEN BERGH, J. C. J. M. \& VERBRUGGEN, H. 1999. Spatial sustainability, trade and indicators: an evaluation of the "ecological footprint". Ecological Economics, 29, 61-72.

VICTOR, D. G., GERLAGH, R. \& BAIOCCHI, G. 2014. Getting serious about categorizing countries. Science, 345, 34-36.

WACKERNAGEL, M. 1994. Ecological footprint and appropriated carrying capacity: A tool for planning toward sustainability. PhD, University of British Columbia.

WACKERNAGEL, M. \& REES, W. E. 1996. Our Ecological Footprint: Reducing Human Impact on the Earth, Philadelphia, US, New Society Publishers.

WEBER, C. L. Uncertainties in constructing environmental multiregional inputoutput models. International input-output meeting on managing the environment, 2008. 1-31.

WEINZETTEL, J., HERTWICH, E. G., PETERS, G. P., STEEN-OLSEN, K. \& GALLI, A. 2013. Affluence drives the global displacement of land use. Global Environmental Change, 23, 433-438.

WEITZEL, M., HÜBLER, M. \& PETERSON, S. 2012. Fair, optimal or detrimental? Environmental vs. strategic use of border carbon adjustment. Energy Economics, 34, Supplement 2, S198-S207.

WICHELNS, D. 2010. Virtual Water: A Helpful Perspective, but not a Sufficient Policy Criterion. Water Resources Management, 24, 2203-2219. 
WICHELNS, D. 2011. Assessing Water Footprints Will Not Be Helpful in Improving Water Management or Ensuring Food Security. International Journal of Water Resources Development, 27, 607-619.

WIEBE, K. S. \& YAMANO, N. 2015. Estimating Consumption-based $\mathrm{CO}_{2}$ Emissions using the OECD ICIO 2015. OECD Directorate for Science, Technology and Innovation.

WIEDMANN, T. 2009. A review of recent multi-region input-output models used for consumption-based emissions and resource accounting. Ecological Economics, 69, 211-222.

WIEDMANN, T. \& LENZEN, M. 2007. On the conversion between local and global hectares in Ecological Footprint analysis. Ecological Economics, 60, 673-677.

WIEDMANN, T., LENZEN, M. \& WOOD, R. 2008. Uncertainty Analysis of the UK-MRIO Model - Results from a Monte-Carlo Analysis of the UK Multi-Region Input-Output Model (Embedded Emissions Indicator). Stockholm Environment Institute at the University of York and Centre for Integrated Sustainability Analysis at the University of Sydney.

WIEDMANN, T. O., SCHANDL, H., LENZEN, M., MORAN, D., SUH, S., WEST, J. \& KANEMOTO, K. 2015. The material footprint of nations. Proceedings of the National Academy of Sciences, 112, 6271-6276.

WILTING, H. C. \& VRINGER, K. 2009. CARBON AND LAND USE ACCOUNTING FROM A PRODUCER'S AND A CONSUMER'S PERSPECTIVE - AN EMPIRICAL EXAMINATION COVERING THE WORLD. Economic Systems Research, 21, 291-310.

WWF 2014. Living Planet Report 2014. Gland, Switzerland: WWF-World Wide Fund for Nature.

WYCKOFF, A. W. \& ROOP, J. M. 1994. The embodiment of carbon in imports of manufactured products: Implications for international agreements on greenhouse gas emissions. Energy Policy, 22, 187-194. 


\section{Summary (Norwegian)}

Utslipp av drivhusgasser og ressursbruk blir ofte allokert basert på regioners nasjonale grenser, hvor nasjonale myndigheter har tilgang til å overvåke og håndheve reguleringer. Slike allokeringer fører ofte til produksjonsbaserte reguleringer, ettersom utslipp og ressursbruk generelt - men ikke alltid - skjer på samme sted hvor varer og tjenester blir produsert.

Det har vært en økende interesse for å allokere utslipp og ressursbruk til forbruk, noe som fører til klimafotavtrykk, spesielt for globale miljøproblemer i en økende globalisert verden. Et klimafotavtrykk kan man tenke på som nasjonale territoriale utslipp (og ressursbruk), etter å ha trukket ifra utslipp som er relatert til produksjon for eksport og lagt til utslipp på grunn av produksjon av import fra andre land.

Industrialiserte land (i-land) har generelt større klimafotavtrykk enn nasjonale territoriale utslipp og bruk av ressurser, noe som gjør dem til netto importører av utslipp og ressurser. I tillegg har netto import-delen $\varnothing \mathrm{kt}$ de siste to tiårene hvor man har estimert klimafotavtrykk. Denne karakteristikken av industrialiserte land som netto importører gjelder ikke nødvendigvis for eksportører av råmaterialer (som for eksempel Australia, Canada og Norge), og det finnes utviklingsland som er netto importører.

Denne utviklingen av i-lands økende netto import har blitt foreslått å være et resultat av økende forbruk i i-land, samtidig som andre land øker deres produksjon og utslipp for å møte etterspørselen, noe som kan potensielt redusere effektene av klima- og miljømessige reguleringer. På bakgrunn av det, har forsvarere av klimafotavtrykk foreslått å regulere lands fotavtrykk, ettersom i-land er importører av utslipp og ressurser.

Når det gjelder drivhusgassutslipp, har det vært mye forskning som har fokusert på å regulere utslipp i handel (for eksempel karbontoll), for å skifte til et forbrukerperspektiv. For ressursbruk, har forskningen $\mathrm{i}$ hovedsak fokusert på å utvikle metoder for å estimere fotavtrykk og å dekomponere resultatene. 
Til tross for potensialet og relevansen til klimafotavtrykk som indikator i reguleringer har det vært relativt lite forskning på bruk av fotavtrykkanalyser i reguleringer. I denne rapporten hevder vi at bruken av klimafotavtrykk i reguleringer er begrenset av utsikkerhetene i estimatene og tolkningene, samt at det er en mangel på tydelige motivasjoner for å ta i bruk klimafotavtrykk. 


\section{Ved Stranden 18}

DK-1061 Copenhagen K

www.norden.org

\section{Global environmental footprints}

Emissions and resources are typically allocated to national territories. There has been increased interest in allocating environmental flows to the final consumption of goods and services. The resulting "environment footprints" are particularly relevant for global environmental problems in a globalised world. Developed countries generally have larger environmental footprints than their national territorial flows, and the gap has tended to increase over the last two decades. Consequently, some have argued that environmental policies should address the environmental footprint. Despite the potential policy relevance, there has been relatively little research on policy applications. While environmental footprints have many advantages, policy applications are limited by estimation and interpretation uncertainty, and by the lack of a clear policy motivation.

TemaNord 2016:532

ISBN 978-92-893-4629-0 (PRINT)

ISBN 978-92-893-4630-6 (PDF)

ISBN 978-92-893-4631-3 (EPUB)

ISSN 0908-6692

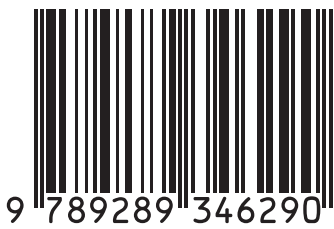

